IZA DP No. 4505

How Sensitive Are Retirement Decisions to

Financial Incentives: A Stated Preference Analysis

Hana Voňková

Arthur van Soest

October 2009 


\title{
How Sensitive Are Retirement Decisions to Financial Incentives: A Stated Preference Analysis
}

\author{
Hana Voňková \\ Netspar, CentER, Tilburg University \\ Arthur van Soest \\ Netspar, CentER, Tilburg University \\ and IZA
}

\section{Discussion Paper No. 4505 \\ October 2009}

\author{
IZA \\ P.O. Box 7240 \\ 53072 Bonn \\ Germany \\ Phone: +49-228-3894-0 \\ Fax: +49-228-3894-180 \\ E-mail: iza@iza.org
}

Any opinions expressed here are those of the author(s) and not those of IZA. Research published in this series may include views on policy, but the institute itself takes no institutional policy positions.

The Institute for the Study of Labor (IZA) in Bonn is a local and virtual international research center and a place of communication between science, politics and business. IZA is an independent nonprofit organization supported by Deutsche Post Foundation. The center is associated with the University of Bonn and offers a stimulating research environment through its international network, workshops and conferences, data service, project support, research visits and doctoral program. IZA engages in (i) original and internationally competitive research in all fields of labor economics, (ii) development of policy concepts, and (iii) dissemination of research results and concepts to the interested public.

IZA Discussion Papers often represent preliminary work and are circulated to encourage discussion. Citation of such a paper should account for its provisional character. A revised version may be available directly from the author. 
IZA Discussion Paper No. 4505

October 2009

\section{ABSTRACT}

\section{How Sensitive Are Retirement Decisions to Financial Incentives: A Stated Preference Analysis}

We study effects of financial incentives on the retirement age using stated preference data. Dutch survey respondents were given hypothetical retirement scenarios describing age(s) of (partial and full) retirement and replacement rate(s). A structural model is estimated in which utility is the discounted sum of within period utilities that depend on employment status and income. Parameters of the utility function vary with observed and unobserved characteristics. Simulations show that the income and substitution effects of pensions as a function of the retirement age are substantial and larger than according to studies using data on actual retirement decisions.

JEL Classification: J22, J26, C81

Keywords: pensions, flexible retirement, gradual retirement, stated choices

Corresponding author:

Hana Voňková

Department of Econometrics

Tilburg University

PO Box 90153

5000 LE Tilburg

The Netherlands

E-mail: h.vonkova@uvt.nl

\footnotetext{
This research was funded by Stichting Instituut GAK and Netspar. We are grateful to Tunga Kantarci, Marcel Kerkhofs, seminar participants in Tilburg, and participants of the conference "Labour Force Participation and Well-being of the 50+ Population" in Utrecht, September 2009, for useful comments.
} 
IZA Discussion Paper No. 4505

October 2009

\section{NON-TECHNICAL SUMMARY}

We analyze stated preference data on retirement. Survey respondents of ages 25 and older in the Netherlands were given hypothetical retirement scenarios describing the age(s) of (partial and full) retirement and corresponding replacement rates. Several types of retirement trajectories were considered - with retirement before, at, or after the standard retirement age (65 years), with and without gradual retirement, and with various replacement rates during partial and full retirement. The data were collected in 2006, 2007 and 2008, partly for the same respondents.

The SP data are used to estimate an intertemporal utility model in which the individual's utility is the discounted sum of within period utilities that depend on employment status (working, partially retired, or (fully) retired) and income in that period. Parameters of the utility function vary with observed and unobserved respondent characteristics and the year of data collection. The estimated model is used to analyze how retirement preferences differ by background characteristics and how they evolve over the survey years. Simulating the choice of the retirement age under actuarially fair and unfair trade-offs, we then analyze how the preferred retirement age changes if pension income levels change irrespective of the retirement age (the "(pension) income effect"), or if the pension benefit accrual induced by delaying retirement changes (the "price" or "substitution" effect).

Confirming most findings in the international literature, we find large effects of financial incentives on the preferred retirement age, often even larger than the effects found with revealed preferences, in line with the fact that we allow for flexible choices without imposing restrictions like mandatory retirement at age 65. Introducing gradual retirement opportunities after the normal retirement age would stimulate participation after age 65 . We find that for trade-offs involving gradual retirement, the replacement rate after full retirement is given much more weight than the replacement rate during gradual retirement. Our simulations with choices between actuarially fair retirement scenarios at ages between 60 and 70 show that an increase in life-time pension incomes by $10 \%$ would lower the average retirement age by 3 months (the income effect). Changing the compensation for delaying retirement from actuarially fair to $50 \%$ of what would be actuarially fair would reduce the average retirement age by 9.7 months. 


\section{Introduction}

The population in many developed countries is ageing and individuals are living longer, leading to a permanent change in the ratio between the numbers of economically active and inactive people. In the Netherlands, for example, expectations are that without changes in pension and retirement policies, the ratio of the number of people aged 65 and above to the economically active population would double in the next 30 years, to over $40 \%$, see Kakes and Broeders (2006). Pension systems will become unsustainable if they do not adjust to this demographic change, see, e.g., Capretta (2007).

One of the problematic features of many pension systems is the existence of generous early retirement schemes which stimulate labour market exit long before the normal retirement age and greatly add to the total cost of the system. See, e.g., Gruber and Wise $(1998,2004)$ for a summary of the evidence in many countries and Kapteyn and De Vos $(1998,2004)$ for the Netherlands. In the Netherlands and other countries, early retirement became common in the 1970's when the social partners sought to "free up" jobs for younger workers facing a high unemployment rate. In the 1990's the government and the social partners realized that the early retirement programs imposed a prohibitive tax on continued work and a start was made to gradually phase them out. A new system of "pre-pension" with fewer employment disincentives was introduced. Pre-pension benefits are, in contrast to the old early retirement benefits, adjusted according to the retirement age, with lower benefits for early retirees. In 2005 other steps to discourage people to retire early were taken. The Dutch government passed legislation that will phase out the tax-favoured treatment of all employer-based early retirement programs, see Capretta (2007). As a consequence, the male labour force participation rate in the age group 55-64 has risen from about $40 \%$ in the 70 's to around $60 \%$ in 2006. For women it rose from less than $20 \%$ to around $40 \%$. Raising the effective retirement age further is often seen as the most feasible way to improve sustainability of the pension system.

Employment after the normal retirement age (usually 65) is very uncommon in many European countries. In the Netherlands, a negligible percentage of employees currently remain at work after age 65. Mandatory retirement is the default, although in principle, firms can rehire workers after age 65 , for example on a temporary and part-time basis. Factors that potentially hamper late retirement are the fact that not all pension funds allow for accumulating pension entitlements after age 65 and the obligation to pay wages for two years after an employee becomes ill.

The more recent debate focuses on creating more flexibility in order to optimize 
the use of the capabilities of older workers, accounting for heterogeneity in preferences and productivity. See, for example, Belloni et al. (2006) for an overview of policies towards flexible retirement in European countries and Bovenberg and Gradus (2008) for a discussion of proposed policy changes in the Netherlands. For the supply side this means, for example, making the retirement age more flexible with rewards for workers who postpone retirement, in the form of actuarially fair pension adjustments and tax arrangements that stimulate later retirement, and creating more opportunities for gradual retirement, see Kantarci and Van Soest (2008). Working after age 65 is an explicit part of the new plans of the Dutch government. For example, eligibility for the first pillar pension (AOW) that provides the minimum subsistence level currently starts at age 65 by default, but a new arrangement makes it possible to delay receiving this in exchange for $5 \%$ higher benefits for every year of delaying. Moreover, the government has launched new plans to delay eligibility to age 67 for everyone.

In order to design successful reforms of retirement policy, it is important to design financially sustainable retirement plans that are attractive for workers. The current paper aims at analyzing workers' preferences for potential retirement plans, with emphasis on plans that allow for full-time or part-time work after age 65 .

In the economic literature, there are many empirical models explaining labour supply behaviour of older workers in an inter-temporal framework. They usually use data on observed actual behaviour of the individuals, i.e. revealed preference (RP) data (see, e.g., Lumsdaine and Mitchell (1999) for an overview and Kapteyn and De Vos (2004), Heyma (2004), Euwals et al. (2007) or Mastrogiacomo et al. (2004) for applications to the Netherlands). In general, revealed preference data capture actual choices made by individuals and are well suited to short-term forecasting of the effects of small departures from the current state of affairs. To study preferences of people in settings which differ a lot from the current state, it is generally better to use stated preference (SP) data relying on the choices of people in hypothetical situations described in survey questions. This method is commonly used in marketing research and transport economics (see, e.g., Louviere et al. (2002)) and is gaining ground in economics (e.g., Barsky et al. (1997) or Revelt and Train (1998)). Respondents are provided with information on hypothetical (but potentially realistic) retirement scenarios and are asked to state their choice between several scenarios, to rank the scenarios, or to rate each of the scenarios. ${ }^{1}$

In our analysis we use stated preference data to analyze preferences of Dutch

\footnotetext{
${ }^{1}$ See Van Soest et al. (2006) for more discussion on the advantages and potential disadvantages of SP and RP data on retirement preferences.
} 
people for early, late and gradual retirement. The main reason for using stated rather than revealed preferences is that we want to estimate preferences for pension plans which do not exist or to which many workers do not have access, such as retirement after age 65 or gradual retirement. Moreover, stated preference data allow for a design where choice opportunities are exactly known and variation in choices is substantial and by construction exogenous to preferences. Stated preference data on retirement of Dutch workers have been collected and analyzed by Nelissen (2001), Bruinshoofd and Grob (2005), Van Soest et al. (2006) and Fouarge et al. (2008). Compared to these earlier studies, we use richer (and more recent) data from various years and focus on estimating a flexible structural model that can be used to compute income and substitution effects on retirement decisions.

Specifically, survey respondents of ages 25 and older in the CentER panel (a representative sample of the Dutch adult population) were given hypothetical retirement scenarios describing the age(s) of (partial and full) retirement and corresponding replacement rates. Several types of retirement trajectories were considered - three trajectories without gradual retirement and with retirement ages 65 (standard retirement age), 67 (late retirement), and 63 (early retirement) and a partial retirement trajectory. Retirement trajectories were evaluated in both rating and choice questions. The data were collected in 2006, 2007 and 2008, partly for the same respondents (leading to an unbalanced panel).

We use the SP data to estimate an intertemporal utility model in which the individual's utility is the discounted sum of within period utilities that depend on employment status (working, partially retired, or (fully) retired) and income in that period. Parameters of the utility function are allowed to depend on observed and unobserved respondent characteristics and on the year of data collection. The estimated model is then used to analyze how retirement preferences differ by background characteristics such as sex, age, and education and how they evolve over the survey years. Simulating the choice of the retirement age under actuarially fair and unfair trade-offs, we then analyze how the preferred retirement age changes if pension income levels change irrespective of the retirement age (the "(pension) income effect"), or if the pension benefit accrual induced by delaying retirement changes (the "price" or "substitution" effect).

Confirming most findings in the international literature, we find large effects of financial incentives on the preferred retirement age. The effects we find are often larger still than the effects found with revealed preferences, which is in line with the fact that we allow for flexible choices without imposing restrictions like mandatory retirement at age 65 . According to our simulations of a choice among actuarially fair 
retirement scenarios at all ages between 60 and 70, an increase in life-time pension incomes by $10 \%$ would lower the average retirement age by 3 months (the "income effect"). Changing the compensation for delaying retirement from actuarially fair to $50 \%$ of what would be actuarially fair would reduce the average retirement age by 9.7 months (the "substitution effect").

This paper is organized as follows. Section 2 describes the questions and the data on stated retirement preferences. Section 3 introduces the model, describes the estimation procedure, and presents the parameter estimates. Section 4 presents the results of simulations and the implied estimates of the income and substitution effects. Section 5 presents some sensitivity checks. Section 6 concludes.

\section{$2 \quad$ Data and Stated Preference Questions}

The questionnaires were included in the Dutch CentERpanel, administrated by CentERdata at Tilburg University. The CentERpanel covers the population in the Netherlands of ages 16 and older. It is composed of over 2000 households in which one or more adults complete questionnaires at home every week through the Internet. The CentERpanel is not restricted to households with prior access to Internet: households without access are provided with access by CentERdata and are given a set-top box that can be connected to their television set and phone line if they do not have a personal computer. (And households without a television set are also given a portable TV.) About $75 \%$ of all panel members respond to the questions in a given weekend.

The Netspar questionnaire about retirement preferences was fielded in June 2006, June 2007 and June 2008. In each wave respondents were asked to evaluate hypothetical and stylized retirement trajectories, designed to be similar to the choices people potentially face, so that they are perceived as realistic. On the other hand, many of the retirement scenarios are currently not offered by all employers, and in order to make sure we measure individual preferences and not demand side constraints, respondents are explicitly asked to assume that their employer will offer each scenario.

To describe a hypothetical situation, respondents first received an introductory text. Respondents younger than 60 were asked to assume that they would still work when turning 60 , that their job at 60 would be similar to their current job and that their employer would fully cooperate with any trajectory. Respondents of age 60 and older got similar instructions with adjusted wording and were asked about the job they had just before turning 60 . Before the scenario questions were asked, 
respondents first reported their number of working hours per week ( $W H$ ), which was then used to formulate the hypothetical retirement scenarios. Respondents younger than 60 were specifically asked how many hours per week they currently worked, while respondents of age 60 and older were asked how many hours per week they worked for pay just before they turned 60 .

Since the trajectories are based on the number of paid working hours $W H$ before retirement and their reduction during gradual and full retirement, it makes little sense to interview people younger than 60 who work zero hours or people older than 60 who worked zero hours at the time they turned 60. Furthermore, some respondents report that they have paid work but also that they have no income. To avoid these problems people who work (or worked when turning 60) for pay less than 3.5 hours per week or whose monthly net income is (or was) less than 45 Euro were not given the scenario questions. Moreover, the questions were not administered to panel members younger than 25, mainly since we thought they probably had not thought much about pensions yet.

This selection leads to a sample in which men and people with high income and high education are overrepresented. The age of respondents is between 25 and 93 years, with medium age of 51 years. The composition of the sample is given in Table 1. In total 2978 observations on 1605 respondents are available. 429 people are interviewed in all three waves, 515 people in two waves and 661 people are interviewed just once.

Respondents got four scenarios describing standard, late, early and partial retirement plans. The scenarios for waves 2006 and 2007 were the following:

Trajectory 1 - standard retirement

$W H$ till age 65 , full retirement at age 65. Disposable pension income is [60\%/65\%/70\%] of last net earnings.

Trajectory 2 - late retirement

$W H$ till age 68, full retirement at age 68. Disposable pension income is [80\%/85\%/90\%] of last net earnings.

Trajectory 3 - early retirement

$W H$ till age 62, full retirement at age 62. Disposable pension income is [45\%/50\%/55\%] of last net earnings.

Trajectory 4 - gradual retirement $W H$ till age [60/62/64], reduced working time to $60 \%$ of $W H$ from age $[60 / 62 / 64]$ till age [63/65/67], full retirement at age [63/65/67]. Disposable labour income from 
[60/62/64] till [63/65/67] is [70\%/75\%/80\%] of earnings at age $[60 / 62 / 64]$; pension income after age [63/65/67] (incl. AOW) is [60\%/65\%/70\%] of net earnings at age [60/62/64].

Table 1: Sample Composition and Background Characteristics

\begin{tabular}{lr}
\hline background characteristics & percent \\
\hline male & 63.6 \\
age 34- & 16.0 \\
age 35-44 & 18.4 \\
age 45-54 & 25.4 \\
age 55-64 & 20.0 \\
age 65+ & 20.2 \\
education low (basis, VMBO) & 26.9 \\
education medium (HAVO, VWO, MBO) & 31.2 \\
education high (HBO, WO) & 41.9 \\
partner & 75.3 \\
income low (net inc 1000-) & 15.6 \\
income medium (net inc 1001-2000) & 55.7 \\
income high (net inc 2001+) & 28.7 \\
work hours 15- & 7.1 \\
work hours 16-32 & 25.1 \\
work hours 33+ & 67.8 \\
own house & 75.0 \\
wave 1 - year 2006 & 34.7 \\
wave 2 - year 2007 & 37.4 \\
wave 3 - year 2008 & 27.9 \\
\hline
\end{tabular}

Note: 2978 observations; 429 respondents participated in all three waves, 515 in two waves, and 661 in one wave.

In each wave respondents were randomly allocated into three groups. Based on this, in all trajectories they were offered one of the three replacement rates given in brackets. ${ }^{2}$ In the partial retirement trajectory, ages for partial and full retirement were also varied across the three groups. ${ }^{3}$ In the 2008 wave, somewhat different trajectories were used, with different replacement rates and a small change in the

\footnotetext{
${ }^{2}$ The replacement rates are low compared to replacement rates of actual retirees (see Fouarge et al. (2008)) but are reasonably representative of subjective expectations of future replacement rates of current employees. For example, Van Dalen et al. (2008) report an average expected replacement rate of $67 \%$.

${ }^{3}$ The order in which the trajectories were presented to the respondents was also randomized.
} 
age of gradual retirement. This was done in order to increase the variation across trajectories and to improve the efficiency of the estimator. The evaluated trajectories in all waves are summarized in Table 2.

Table 2: Description of Pension Trajectories in SP Questions

\begin{tabular}{|c|c|c|c|c|}
\hline \multirow{2}{*}{ trajectory } & & \multicolumn{2}{|c|}{ waves 1,2} & \multirow{2}{*}{$\frac{\text { wave } 3}{\text { g1 g2 g3 }}$} \\
\hline & & g1 g2 & g3 & \\
\hline \multirow[t]{2}{*}{1 - standard } & age full & 6565 & 65 & 656565 \\
\hline & rr full & 6065 & 70 & 657075 \\
\hline \multirow[t]{2}{*}{2 - late } & age full & 6868 & 68 & 686868 \\
\hline & rr full & 8085 & 90 & $75 \quad 8595$ \\
\hline \multirow[t]{2}{*}{3 - early } & age full & 6262 & 62 & $62 \quad 62 \quad 62$ \\
\hline & rr full & 4550 & 55 & $50 \quad 50 \quad 50$ \\
\hline \multirow[t]{4}{*}{4 - partial } & age part & 6062 & 64 & 616164 \\
\hline & age full & 6365 & 67 & 656568 \\
\hline & rr part & 7075 & 80 & 1007585 \\
\hline & rr full & 6065 & 70 & 607080 \\
\hline
\end{tabular}

Note: In each wave, people were randomly assigned to one of three groups g1, g2 or g3, with different replacement rates. Each respondent evaluated four trajectories defined by partial retirement age (age part), replacement rate in partial retirement (rr part), full retirement age (age full) and replacement rate in full retirement period (rr full).

Respondents evaluated the hypothetical trajectories of standard, late, early and partial retirement by rating each trajectory and by choosing between pairs of trajectories. In the four rating questions the attractiveness of each retirement trajectory was assessed on a ten point scale from 1 (very unattractive) to 10 (very attractive). The answers will be denoted by R1, R2, R3 and R4 for the four scenarios of benchmark, late, early and gradual retirement, respectively. In the two choice questions respondents were asked to choose between two trajectories - standard and late retirement (trajectories 1 and 2) and standard and gradual retirement (trajectories 1 and 4). The reported choices are denoted by $\mathrm{C} 1$ and $\mathrm{C} 2$, respectively.

In Figure 1, histograms of the evaluations of the standard retirement trajectory (R1) and their comparisions with the evaluations of late retirement trajectory (R1$\mathrm{R} 2$ ), early retirement trajectory (R1-R3) and gradual retirement trajectory (R1-R4) are given for the year 2006 and the randomization group of respondents g3 in Table $2{ }^{4}$ In Table 3, means and standard errors of evaluations of the four retirement

\footnotetext{
${ }^{4}$ Looking at the differences instead of the levels eliminates response scale differences between
} 
Figure 1: Histograms of the evaluations of the standard retirement trajectory (benchmark) and their comparison with the evaluations of late, early and partial retirement trajectories for wave 1, group 3 .

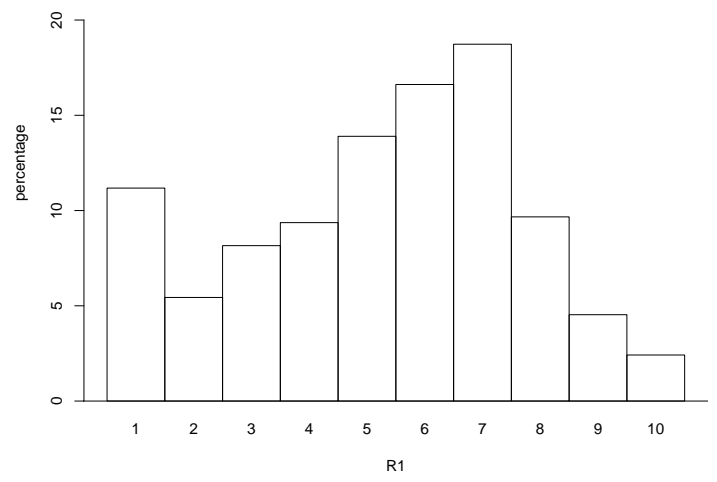

(a) benchmark

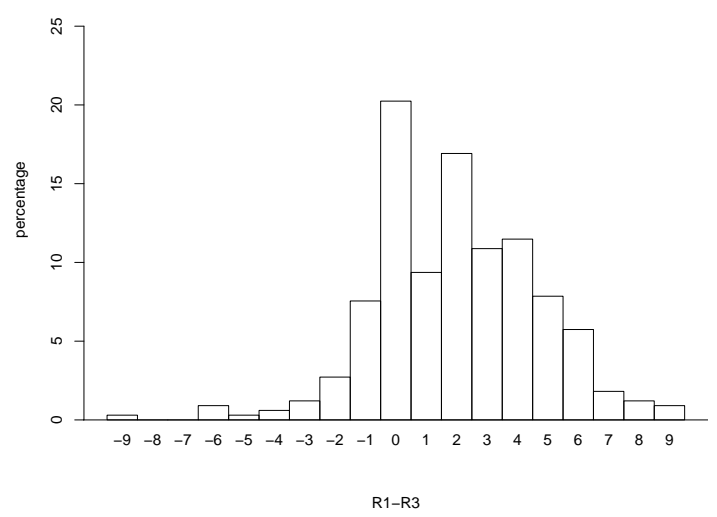

(c) benchmark - early retirement

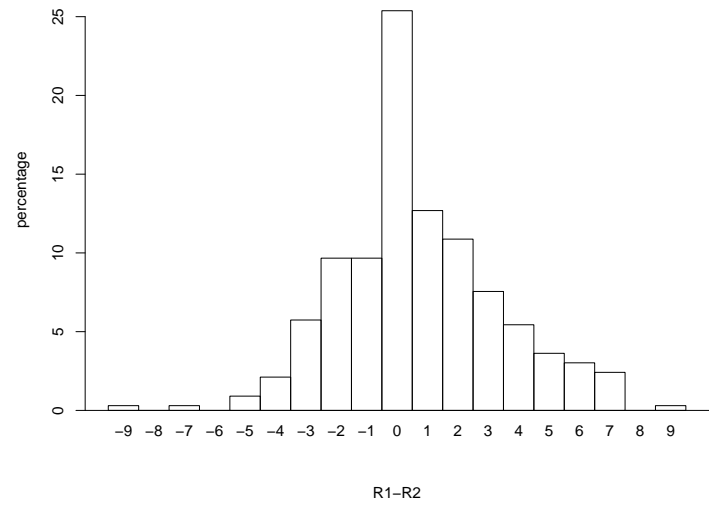

(b) benchmark - late retirement

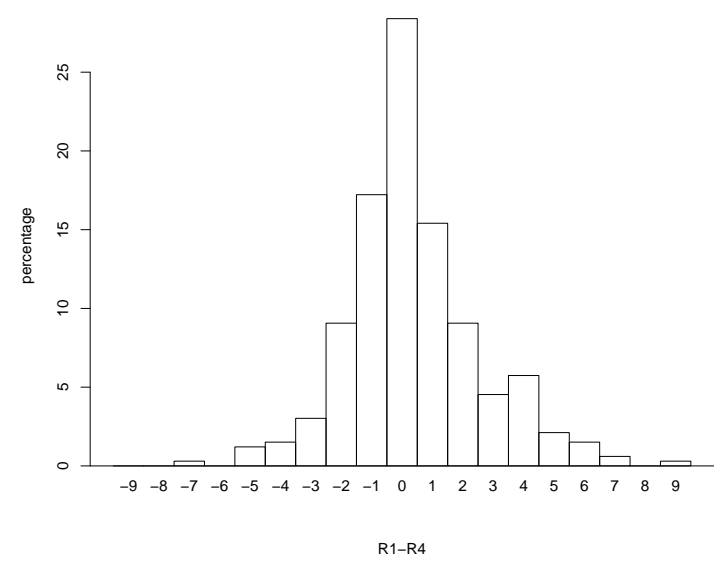

(d) benchmark - partial retirement 
trajectories (R1, R2, R3 and R4) as well as of the choices (C1 and C2) are presented, separately for each wave and for each of the three random assignment groups. The mean of the benchmark evaluations in Figure 1(a) is 5.27 (see Table 3), with quite large dispersion. Possible reasons for this may be genuine heterogeneity in how attractive this specific scenario is to different respondents, the fact that different respondents may have different response scales, or noise in the assessments.

Table 3: Means and Standard Deviations of Ratings and Choices

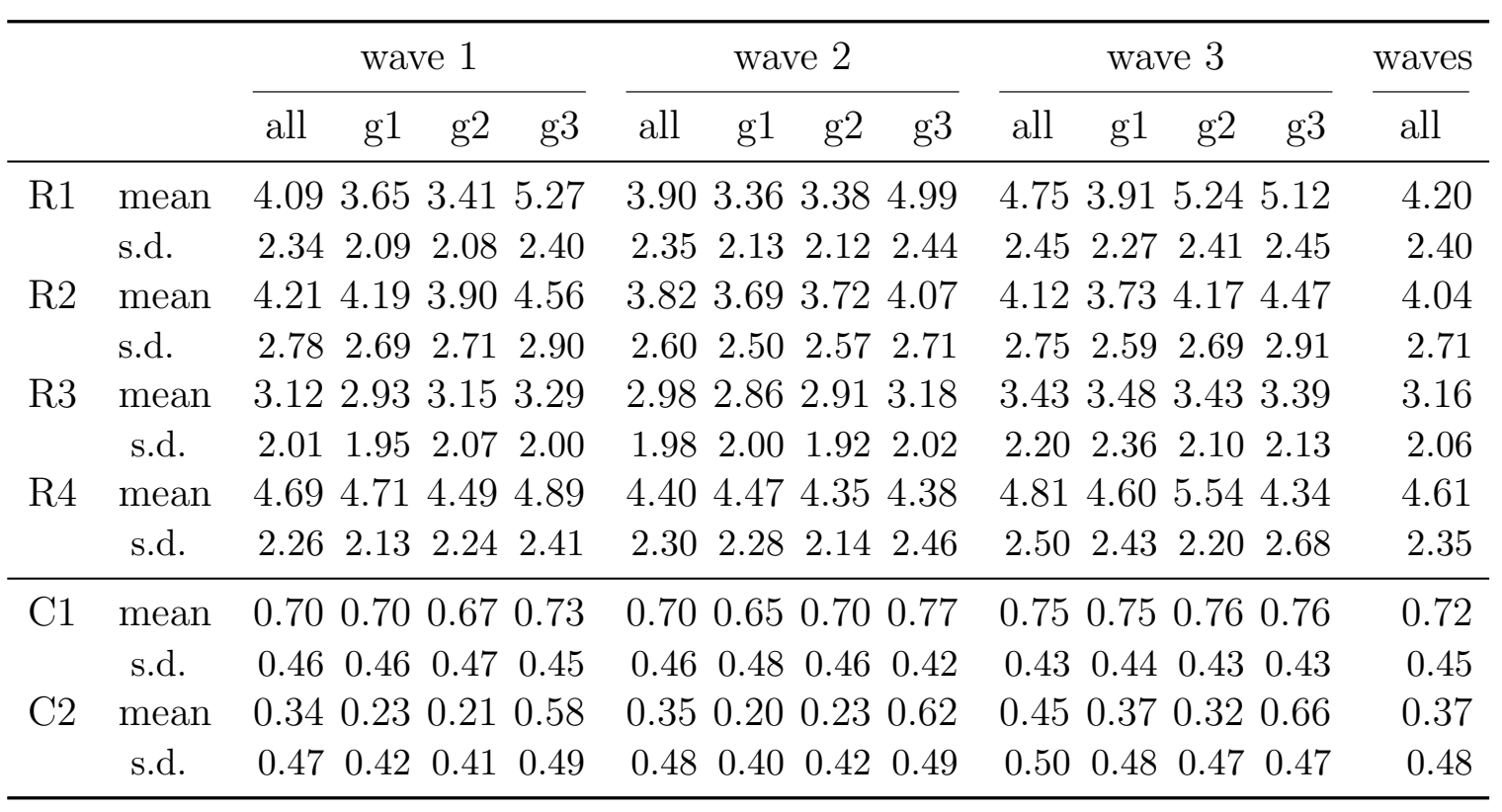

Note: choices $\mathrm{C} 1$ and $\mathrm{C} 2$ coded as 1 if benchmark trajectory (R1) is chosen; 0 otherwise.

The histogram in Figure 1(b) shows that the benchmark is preferred to late retirement more often than the other way around. This corresponds to the fact that in the choice question $\mathrm{C} 1$ (standard versus late retirement trajectory), $73 \%$ of people choose the standard retirement trajectory (see Table 3). Figure 1(c), where the benchmark is compared to the early retirement scenario, shows that most people give lower ratings to early retirement than to the benchmark. On the other hand, the symmetric distribution of differences R1-R4 (benchmark minus gradual retirement) in Figure 1(d) shows that the group preferring the benchmark to gradual retirement is about as large as the group with the opposite preference. In the choice question $\mathrm{C} 2$ (standard versus gradual retirement), $58 \%$ of people chose the standard retirement trajectory (see Table 3).

respondents (cf. Van Soest et al. 2006). 
There are some statistically significant changes in the average ratings between 2006 and 2007; in particular, many of the mean ratings in 2007 are lower than the corresponding means in 2006, suggesting that respondent evaluations have become more negative. Where comparable, ${ }^{5}$ the means in 2008 are not significantly different from those in 2006, but there are some significant differences between 2008 and 2007.6

Comparing the mean evaluations of the three groups in a given year for a given question R1, R2 or R3 shows how the evaluations vary with the replacement rate. Group g1 got the lowest and group g3 the highest replacement rate, except for R3 in 2008, where the replacement rate for all groups was $50 \%$ (see Table 2). The evaluation of a retirement scenario with a higher replacement rate is either significantly higher or not statistically different from that of the same retirement scenario with a lower replacement rate. The biggest difference between the groups is found for question R1 (standard retirement trajectory), where trajectories with replacement rates lower than $70 \%$ are evaluated significantly less than the trajectories with replacement rates $70 \%$. This can be due to the general preference for defaults the default retirement age in the Netherlands is 65 with an accompanying pension income equal approximately to $70 \%$ of the last earned wage.

Gradual retirement trajectories differ in the replacement rate during partial retirement as well as after full retirement, but also in the age of partial retirement and the age of full retirement. This makes it impossible to directly interpret the differences in evaluations of R4 across groups and years. In order to understand what these evaluations imply, we will use the structural model introduced in the next section.

Table 4 compares responses to rating and choice questions of the same respondents in the same wave. Respondents who prefer the standard retirement trajectory to the late retirement trajectory in the choice question $(\mathrm{C} 1=1)$ also tend to evaluate the standard retirement trajectory higher than the late retirement trajectory in the rating questions $(\mathrm{R} 1>\mathrm{R} 2)$. Specifically, $47.4 \%$ of the $\mathrm{C} 1=1$ respondents rate the standard retirement trajectory higher, $34.6 \%$ give the same ratings for both trajectories and $18.1 \%$ rate the standard retirement trajectory lower than late retirement. For $\mathrm{C} 1=1$ respondents, the mean ratings of the standard and late retirement trajectories are 4.12 and 3.26, resp. Of the other respondents who chose the late retirement trajectory over standard retirement $(\mathrm{C} 1=0), 13.4 \%$ rated the late retirement tra-

\footnotetext{
${ }^{5}$ for example for question R1, group g3 in 2006 got the same replacement rates as group g2 in 2008; see Table 2

${ }^{6} \mathrm{P}$-values lower than 0.05 are obtained for R2 - group g2 in 2007 and group g3 in 2008 - and for R3 group g2 in 2007 and any of the groups in 2008.
} 
jectory lower than the standard retirement trajectory $(\mathrm{R} 1>\mathrm{R} 2)$. The other $\mathrm{C} 1=0$ respondents either gave a higher rating to the late retirement trajectory $(65.5 \%)$ or rated the two trajectories equally $(21.1 \%)$. The mean evaluation of the late retirement trajectory (mean $\mathrm{R} 2=6.01$ ) by $\mathrm{C} 1=0$ respondents is significantly higher than their mean evaluation of the standard retirement trajectory (mean $\mathrm{R} 1=4.41$ ).

Table 4: Ratings and Choices

\begin{tabular}{lccrrrr}
\hline & \multicolumn{3}{c}{ percentage } & \multicolumn{2}{c}{ mean } \\
$\mathrm{C} 1=1$ & 47.39 & 34.56 & 18.05 & & 4.12 & 3.26 \\
$\mathrm{C} 1=0$ & 13.40 & 21.12 & 65.48 & & 4.41 & 6.01 \\
& & & & & \\
& $\mathrm{R} 1>\mathrm{R} 4$ & $\mathrm{R} 1=\mathrm{R} 4$ & $\mathrm{R} 1<\mathrm{R} 4$ & $\mathrm{R} 1$ & $\mathrm{R} 4$ \\
$\mathrm{nyyyyy} \mathrm{C} 2=1$ & 44.37 & 34.02 & 21.60 & & 4.69 & 3.87 \\
$\mathrm{C} 2=0$ & 16.03 & 25.07 & 58.90 & 3.91 & 5.06 \\
\hline
\end{tabular}

Note: In the first choice question respondents could choose the standard retirement trajectory $(\mathrm{C} 1=1)$ or the late retirement trajectory $(\mathrm{C} 1=0)$. For each of these two choices the table shows how often the rating of the standard retirement trajectory was higher than the late retirement trajectory $(R 1>R 2)$, the same $(R 1=R 2)$, or lower $(R 1<R 2)$. Similarly, in the second choice question respondents chose between the standard retirement trajectory $(\mathrm{C} 2=1)$ and the gradual retirement trajectory $(\mathrm{C} 2=0)$ and the table shows how the ratings (R1 and R4) compared to the choice.

In the second choice question $\mathrm{C} 2$, respondents could choose between standard and gradual retirement. Again, on average, the choices are in line with the ratings (see Table 4) but there are also many inconsistencies. For example, $78.4 \%$ of the respondents who prefer the benchmark trajectory to the gradual retirement trajectory $(\mathrm{C} 2=1)$ rate the standard retirement trajectory higher $(\mathrm{R} 1<\mathrm{R} 4)$ or in the same way $(\mathrm{R} 1=\mathrm{R} 4)$, while for $21.6 \%$ the ratings are inconsistent with the choice. The inconsistencies may be due to reporting errors in both choice and rating questions, and Table 4 makes clear that it is important to account for these errors in the structural model. 


\section{Model of Stated Retirement Preferences}

We use a life-cycle model similar but more general than the one of Van Soest et al. (2006). We assume that the total utility of retirement trajectory $q$ for individual $i=1, \ldots, I$ in wave $s=1,2,3, U_{i s}^{q}$, has the following form:

$$
U_{i s}^{q}=\sum_{t=60}^{100} \rho^{t-60} U_{i s t}^{q},
$$

where $U_{i s t}^{q}$ is the utility at age $t=60, \ldots, 100$ and $\rho$ is the discount factor. The time horizon is fixed at 100 years of age and thus each work - retirement trajectory covers ages from 60 (the earliest retirement age in the scenarios) to 100.

$U_{i s t}^{q}$ is modelled as follows:

$$
\begin{array}{rlrl}
U_{i s t}^{q} & =\alpha_{i s}^{0}+\alpha_{i s t}^{p} P_{i s t}^{q}+\alpha_{i s t}^{r} R_{i s t}^{q}+\alpha_{i s}^{y} y_{i s t}^{q}+\alpha^{p y} P_{i s t}^{q} y_{i s t}^{q} & \\
\alpha_{i s}^{a}=X_{i s} \beta^{a}+\gamma_{i s}^{a}+\delta_{s}^{a} & a=0, y \\
\alpha_{i s t}^{b}=X_{i s} \beta^{b}+\gamma_{i s}^{b}+\delta_{s}^{b}+\eta^{b} t & b=p, r \\
\gamma_{i}^{c} \stackrel{i i d}{\sim} \mathrm{N}\left(0, \sigma_{c}^{2}\right) & c=0, p, r, y \\
\gamma_{i}^{c} \perp X_{i s} & c=0, p, r, y
\end{array}
$$

Here $P$ and $R$ are dummies for partial and full retirement, respectively, and $\perp$ denotes statistical independence. At each age $t$, a person can be not retired $(P=$ $R=0)$ and working pre-retirement hours $(W H)$, partially retired $(P=1, R=0)$ and working $60 \%$ of pre-retirement hours, or fully retired $(P=0, R=1)$. $y_{t}$ denotes logarithm of the replacement rate, that is the log of net (pension and/or labour) income at age $t$ as a fraction of pre-retirement net earnings. For example, if after tax pension income during full retirement is $70 \%$ of pre-retirement after tax earnings then $y=\log (0.7)$ at that age. Note that the replacement rates vary by design of each scenario, independent of individual characteristics. Before (gradual) retirement, we have $y=\log (1)=0$.

As apparent from equation(4), $\alpha_{i s t}^{p}$ is the preference parameter for partial retirement, determining the utility of partial retirement compared to the utility of not retired at age $t$ for respondent $i$ in wave $s$. The parameter is assumed to depend on a set of observed characteristics $X_{i s}$ at the time of survey $s$, like gender, age, and education. Moreover, $\alpha_{i s t}^{p}$ can depend on unobserved characteristics of person $i, \gamma_{i}^{p}$, assumed to be normally distributed with expected value 0 and standard deviation $\sigma^{p}$, independent of observed characteristics $X_{i s}$. Wave effects are captured by the parameters $\delta_{s}$ and the effects of age $t$ in each period considered by $\eta_{t}^{p}$. 
The preference parameter $\alpha_{i s t}^{r}$ for full retirement has the same specification as $\alpha_{i s t}^{p}$. We expect that the parameters $\eta^{p}$ and $\eta^{r}$ will be positive because people's valuation of retirement increases with age, due to e.g. deteriorating health.

The coefficient $\alpha_{i s}^{y}$ determines the influence of an income change in full retirement. It is assumed to depend on the observed characteristics $X_{i s}$, an unobserved heterogeneity term $\gamma^{y}$ and a survey wave effect $\delta_{s}$. Thus $\alpha_{i s}^{y}$ is not allowed to vary with age $t$. The reason is that, with the given design, there would be a high negative correlation between $t R_{t}$ and $t y_{t}$ preventing estimation of both coefficients. To solve this problem more variation in the replacement rates in the scenarios would have been needed, but this would also involve the drawback of making the scenarios less realistic.

The influence of an income change in partial retirement on utility is captured by $\alpha_{i s}^{y}+\alpha^{p y}$. The parameter $\alpha^{p y}$ reflects the difference between the effects of income on utility in periods of partial and full retirement. Note that $y_{i s t}^{q}$ when not retired is always equal to $\log (1)=0$, which is why no second interaction term (between $\log (y)$ and $R$ ) could be included.

The coefficient $\alpha_{i s}^{0}$ determines the level of utility regardless of labour force status and income. When comparing utility of two trajectories, this coefficient does not play any role. It depends on observed and unobserved characteristics of the individual and may vary across the three waves of the survey, but it does not depend on age - age effects on $\alpha_{i s}^{0}$ would not be identified (because we always consider the age range $60-100)$.

As described in section 2 , the respondents rated four pension trajectories on a discrete scale from 1 to 10 . The observed ratings $R_{i s}^{q}, q=1, \ldots, 4$ are modeled as follows:

$$
\begin{array}{lc}
V_{i s}^{q}=U_{i s}^{q}+\epsilon_{i s}^{1 q} & q=1,2,3,4 \\
C_{i s}^{q}=k \Leftrightarrow \mu_{k-1}<V_{i s}^{q} \leq \mu_{k} & k=1, \ldots, 10 \\
\epsilon_{i s}^{1 q} \stackrel{i i d}{\sim} \mathrm{N}\left(0, \sigma_{1}^{2}\right) & \\
\epsilon_{i s}^{1 q} \perp X_{i s}, \gamma_{i}^{c} & c=0, p, r, y
\end{array}
$$

$\epsilon^{1}$ is the "reporting error" in the rating questions. Threshold parameters $-\infty=$ $\mu_{0}<\mu_{1}<\ldots \mu_{9}<\mu_{10}=\infty$ are assumed to be the same for all respondents. For identification, $\mu_{1}$ is set to 1.5 and $\mu_{9}$ to 9.5.

In the choice questions respondents choose between the standard retirement trajectory and late retirement $(\mathrm{C} 1)$ or partial retirement $(\mathrm{C} 2)$. An observed choice of the standard retirement trajectory is coded by 1 , a choice of the alternative is coded 
by 0 . Observed choices $C_{i s}^{1}$ and $C_{i s}^{2}$ are modelled as follows:

$$
\begin{array}{lrl}
C_{i s}^{1}=1 \Leftrightarrow U_{i s}^{1}-U_{i s}^{2}>\epsilon_{i s}^{21} & C_{i s}^{1}=0 & \text { otherwise } \\
C_{i s}^{2}=1 \Leftrightarrow U_{i s}^{1}-U_{i s}^{4}>\epsilon_{i s}^{22} & C_{i s}^{2}=0 & \text { otherwise } \\
\epsilon_{i s}^{2 q} \stackrel{i i d}{\sim} \mathrm{N}\left(0, \sigma_{2}^{2}\right) & \\
\epsilon_{i s}^{2 q} \perp X_{i s}, \gamma_{i}^{c}, \epsilon_{i s}^{1} & c=0, p, r, y
\end{array}
$$

The optimization errors in choice questions $q=1,2$ are denoted as $\epsilon^{2 q}$. Their variance can be different from that of $\epsilon_{i s}^{1}$ because noise levels in ratings and choices may well differ (see Louviere et al. (2002)).

\subsection{Estimation}

The estimation of our model is similar to the estimation of a mixed logit model and other random coefficient models (cf., e.g., Revelt and Train (1998)). These models are usually estimated by simulated maximum likelihood. The likelihood contribution for individual $i$ conditional on unobserved heterogeneity parameters $\vec{\gamma}_{i}=\left(\gamma_{i}^{0}, \gamma_{i}^{p}, \gamma_{i}^{r}, \gamma_{i}^{y}\right)^{\prime}$ can be written as a product of the probabilities of the observed outcomes $R_{i s}^{q}, q=1, \ldots, 4$ and $C_{i s}^{q}, q=1,2$, the answers to the ratings and choice questions of respondent $i$ in all waves $s=1,2,3 .{ }^{7}$ Model assumptions in 7 and 11 imply that these probabilities can be written as follows:

$$
\begin{array}{ll}
P\left(C_{i s}^{q}=k \mid \mathcal{A}_{i s}, \vec{\gamma}_{i}\right)=\Phi\left(\frac{\mu_{k}-U_{i s}^{q}}{\sigma_{1}}\right)-\Phi\left(\frac{\mu_{k-1}-U_{i s}^{q}}{\sigma_{1}}\right) & k=1, \ldots, 10 \\
P\left(C_{i s}^{1}=l \mid \mathcal{A}_{i s}, \vec{\gamma}_{i}\right)=\Phi\left((-1)^{1-l} \frac{U_{i s}^{1}-U_{i s}^{2}}{\sigma_{2}}\right) & q=1,2,3,4 \\
P\left(C_{i s}^{2}=l \mid \mathcal{A}_{i s}, \vec{\gamma}_{i}\right)=\Phi\left((-1)^{1-l} \frac{U_{i s}^{1}-U_{i s}^{4}}{\sigma_{2}}\right) & l=0,1,
\end{array}
$$

where $\mathcal{A}_{i s}=\left\{X_{i s}, P_{i s t}^{q}, R_{i s t}^{q}, y_{i s t}^{q}, \beta^{c}, \delta_{s}^{c}, \eta^{b}, \quad c=0, p, r, y, \quad b=p, r, \quad t=0, \ldots, 40\right\}$ is the set of all relevant individual and trajectory characteristics and parameters and $\Phi$ is the standard normal distribution function.

The (unconditional) likelihood contribution for individual $i$ can be written as

\footnotetext{
${ }^{7}$ In case of item non-response (if a respondent answers "don't know" or "refuse" to a specific question) or unit nonresponse (if a respondent does not participate in a given survey wave) the corresponding probability is replaced by 1 . (We work with the full unbalanced panel.)
} 
a four dimensional integral:

$$
\iiint \int \prod_{s=1}^{3} \prod_{q=1}^{6} P\left(C_{i s}^{q}=k_{i s}^{q} \mid \mathcal{A}_{i s}, \vec{\gamma}_{i}\right) f\left(\vec{\gamma}_{i}\right) d \vec{\gamma}_{i}
$$

where $f$ denotes the density of the vector of random coefficients. The assumption in equation (5) implies that the density of $\vec{\gamma}_{i}$ can be rewritten as a product of univariate normal densities:

$$
f\left(\vec{\gamma}_{i}\right)=\prod_{c=0, p, r, y} \phi\left(\gamma_{i}^{c} / \sigma_{c}\right) / \sigma_{c}
$$

Since it is not feasible to compute the integral numerically we approximate the integral using simulated values of the random coefficients and use simulated maximum likelihood (see, e.g., Gourieroux and Monfort (1996)), replacing (18) by:

$$
\frac{1}{\operatorname{Sim}} \sum_{\operatorname{sim}=1}^{\operatorname{Sim}} \prod_{s=1}^{3} \prod_{q=1}^{6} P\left(C_{i s}^{q}=k_{i s}^{q} \mid \mathcal{A}_{i s}, \tilde{\gamma}_{i, \mathrm{sim}}^{c}, c=0, p, r, y\right),
$$

where Sim is the number of simulations and $\tilde{\gamma}_{i, \text { sim }}^{c}$ is a random draw from a normal distribution with mean zero and standard deviation $\sigma_{c}$. Usually a large number of pseudo-random draws is needed to assure a reasonably low simulation error in the estimated parameters. The number of draws and thus the time the estimation procedure takes can be substantially reduced (keeping the same simulation variance) by using quasi-random numbers of Halton sequence (see Train (2003)). The number of draws per individual is $500 .^{8}$

Estimates of the covariance matrix of the parameter estimates are based upon the asymptotic result from Gourieroux and Monfort (1991). One of the key assumptions is that $\sqrt{N} / \operatorname{Sim} \rightarrow 0$ if $N$, $\operatorname{Sim} \rightarrow \infty$, where $N$ is number of observations and Sim number of simulations for each respondent (see, e.g., Gourieroux and Monfort (1996) for details on simulated maximum likelihood).

\subsection{Estimation Results}

Parameter estimates are presented in Table 5. The first column ( " $\alpha$ ") presents the coefficients $\beta^{0}$, which determine $\alpha^{0}$, the utility in year $t$ of the pre-retirement benchmark status $(y=0, D=0, P=0)$. Since the other parameters drive the change in utility due to a deviation from this benchmark, $\beta^{0}$ affects the ratings of the scenarios but not the choices. Many of the parameters in $\beta_{0}$ are significant,

\footnotetext{
${ }^{8}$ Estimated coefficients using $\operatorname{Sim}=600$ or $\operatorname{Sim}=700$; were virtually identical to those with $\operatorname{Sim}=500$. For the four random coefficients we use Halton sequences with primes 3, 5, 7 and 11 .
} 
implying substantial heterogeneity in the (absolute) utility ratings. For example, the age groups 45-64 give less positive utility ratings than the younger and older age groups, and the lower income groups give more positive ratings than the middle and high income groups. Respondents with a small part-time job are more positive than those who work(ed) longer hours. Note that this may not be a causal effect - it may be due to common preference factors that drive both current working hours and desired future working hours. The same remark applies to all included employment status variables.

The large and significant estimate of $\gamma_{0}$ implies that there is also substantial heterogeneity that is not captured by the observed respondent characteristics. The significant estimates of $\delta_{2}$ and $\delta_{3}$ imply that utility ratings in 2007 and 2008 were less and more positive than those in 2006, respectively. These time effects might reflect, for example, temporary effects due to the political debate at the time of the survey.

Parameters $\beta^{p}$ and $\beta^{r}$ in the second column (" $\left.\alpha^{p "}\right)$ and third column (" $\alpha$ ") determine how the differences in utility between partial retirement and pre-retirement $\left(\alpha^{p}\right)$ and between full retirement and pre-retirement $\left.\alpha^{r}\right)$ vary with respondent characteristics. We do not find a significant effect of gender, education, home ownership or partnership status. The utility of partial retirement is significantly lower for the older birth cohorts, while no significant cohort effect on the utility of full retirement is found. Keeping the other variables constant, the higher income respondents attach higher utility to working part-time or not working at all, reflecting a life-time income effect if leisure is a normal good. Part-time workers have the largest preference for partial as well as full retirement. Full-time workers value partial retirement more than non-workers but less than part-timers.

The parameters $\delta_{s}^{p}$ and $\delta_{s}^{r}$ indicate how the evaluations of partial and full retirement vary with the time of data collection. The utility of part-time work (compared to the utility of full-time work) is significantly lower in 2008 than in 2006 or 2007, suggesting that preferences for partial retirement have decreased.

The significant estimate of $\eta^{r}$ implies that respondents attach increasing utility to full retirement when they get older. This may reflect that expected health deterioration at older ages is seen as an impediment to full-time work. The small and insignificant estimate of $\eta^{p}$ implies that such an impediment much less applies to part-time work and suggests that partial retirement might make it easier to keep people with a health concern in the labour market. 
Table 5: Estimation Results

\begin{tabular}{|c|c|c|c|c|c|c|c|c|}
\hline & \multicolumn{2}{|c|}{$\alpha^{0}$} & \multicolumn{2}{|c|}{$\alpha^{p}$} & \multicolumn{2}{|c|}{$\alpha^{r}$} & \multicolumn{2}{|c|}{$\alpha^{y}$} \\
\hline & Coeff. & T-val. & Coeff. & T-val. & Coeff. & T-val. & Coeff. & T-val. \\
\hline const & -0.471 & -4.777 & 0.039 & 0.558 & -0.771 & -4.552 & 0.470 & 2.936 \\
\hline male & 0.018 & 0.619 & 0.020 & 0.680 & -0.027 & -0.340 & 0.085 & 1.022 \\
\hline age $45-54$ & -0.149 & -5.070 & -0.006 & -0.209 & 0.121 & 1.518 & -0.085 & -1.056 \\
\hline age $55-64$ & -0.100 & -3.141 & -0.054 & -1.694 & 0.018 & 0.207 & -0.176 & -1.994 \\
\hline age $65+$ & 0.091 & 2.895 & -0.063 & -2.046 & -0.051 & -0.616 & 0.102 & 1.172 \\
\hline education mid & -0.020 & -0.668 & 0.011 & 0.381 & 0.041 & 0.517 & 0.023 & 0.279 \\
\hline education high & 0.029 & 0.964 & 0.043 & 1.489 & 0.056 & 0.711 & 0.118 & 1.429 \\
\hline partner & -0.057 & -2.071 & 0.024 & 0.905 & 0.056 & 0.762 & -0.033 & -0.440 \\
\hline income mid & -0.102 & -2.755 & 0.066 & 1.747 & 0.111 & 1.085 & 0.077 & 0.734 \\
\hline income high & -0.130 & -2.918 & 0.094 & 2.047 & 0.187 & 1.510 & 0.141 & 1.104 \\
\hline work hours 16-32 & -0.135 & -2.827 & 0.175 & 3.477 & 0.286 & 2.125 & 0.232 & 1.671 \\
\hline work hours $33+$ & -0.105 & -2.056 & 0.131 & 2.468 & 0.163 & 1.139 & 0.105 & 0.712 \\
\hline own house & -0.047 & -1.750 & -0.017 & -0.631 & 0.012 & 0.160 & -0.065 & -0.865 \\
\hline$\sigma($ s.d. of $\gamma)$ & 0.198 & 20.643 & 0.168 & 11.387 & 0.001 & 0.096 & 0.357 & 15.384 \\
\hline$\delta_{2}$ & -0.084 & -3.436 & 0.024 & 0.853 & 0.130 & 1.781 & 0.107 & 1.494 \\
\hline$\delta_{3}$ & 0.059 & 2.040 & -0.154 & -4.002 & -0.099 & -1.133 & -0.077 & -0.871 \\
\hline$\eta$ & & & 0.022 & 0.289 & 0.229 & 2.060 & & \\
\hline & Coeff. & T-val. & & & & & & \\
\hline$\alpha^{p y}$ & -0.556 & -4.720 & & & & & & \\
\hline$\rho$ & 0.889 & $\begin{array}{r}\text { S.e. } \\
0.005\end{array}$ & & & & & & \\
\hline$\sigma_{1}$ & 2.030 & 0.024 & & & & & & \\
\hline$\sigma_{2}$ & 0.597 & 0.031 & & & & & & \\
\hline \multicolumn{9}{|c|}{ Thresholds in Rating Equation } \\
\hline$\mu_{1}$ & 1.5 & & & & & & & \\
\hline$\mu_{2}$ & 2.365 & 0.023 & & & & & & \\
\hline$\mu_{3}$ & 3.272 & 0.032 & & & & & & \\
\hline$\mu_{4}$ & 4.025 & 0.037 & & & & & & \\
\hline$\mu_{5}$ & 5.000 & 0.044 & & & & & & \\
\hline$\mu_{6}$ & 5.958 & 0.051 & & & & & & \\
\hline$\mu_{7}$ & 7.097 & 0.058 & & & & & & \\
\hline$\mu_{8}$ & 8.524 & 0.058 & & & & & & \\
\hline$\mu_{9}$ & 9.5 & & & & & & & \\
\hline
\end{tabular}

Although we have included many observed characteristics of respondents, we still find significant unobserved heterogeneity in $\alpha^{p}$. On the other hand, unobserved heterogeneity in $\alpha^{r}$ is virtually zero (and insignificant).

The last column indicates the effect of the log replacement rate during full or 
partial retirement. A larger replacement rate is valued significantly less by the age cohort $55-64$ than by the youngest and oldest age cohort. The effects of other respondent characteristics are not significant at the $5 \%$ level. Still, the large and significant estimate of the unobserved heterogeneity parameter $\gamma^{y}$ shows that there is substantial dispersion in how respondents value a higher replacement rate.

The negative estimate of $\alpha^{p y}$ implies that the utility from an increase in income is significantly lower during partial retirement than during full retirement. The estimated value of the discount factor $\rho$ is equal to 0.89 and it is very accurately determined with a standard error of only 0.005. This also captures the mortality rate since mortality is not explicitly taken into account.

Finally, the estimated standard deviations of the error terms imply that the amount of noise is much larger in the ratings than in the choices: the estimate of $\sigma_{1}$ is more than three times larger than that of $\sigma_{2}$. For a given level of noise, ratings of a set of scenarios would provide more information than only the choice among these scenarios, but this difference is counteracted by the difference in noise levels.

\section{Simulations}

In this section, we discuss the implications of the model estimates. We first discuss how the preferences for early and late full and gradual retirement vary with background characteristics. Then we show how people respond to a change in pension income in partial and full retirement. We also simulate choices among actuarially neutral trajectories with retirement age varying from 60 to 70 . Finally, we analyze the (pension) income and substitution effects on the preferred age of retirement. The simulations are all based on the estimated parameters in Table 5 of the previous section.

\subsection{Comparing to the Benchmark}

Simulated probabilities presented in Tables 6 and 7 are computed in the following way. For each respondent $i$ in each year $s$, we first compute the probability of choosing the alternative scenario if the choice is between this alternative and the benchmark scenario (retirement at age 65 , replacement rate $70 \%$ ) only. This probability takes into account observed and unobserved individual heterogeneity and the optimization error in the choice questions $\left(\epsilon_{2}\right)$. These probabilities are averaged over the sub-samples of respondents with observed characteristics as indicated in the tables. For example, the number 1.36 in the first row ("Late 1") and eighth 
column of Table 6 indicates that the probability that a person of age 55-64 chooses the Late 1 trajectory rather than the benchmark retirement trajectory is $1.36 \%$.

The scenarios are defined in columns 2-5 of the table; they are taken from Van Soest et al. (2006). The first six - Late 1 to Early 3 - do not involve gradual retirement. Scenarios Late 1, Late 2 and Late 3 describe late retirement at age 70 with net pension incomes equal to $90 \%, 100 \%$ and $110 \%$ of net pre-retirement earnings, respectively. Simulated probabilities show that most people prefer the benchmark to these late retirement trajectories. In particular, only $3 \%$ of the people would prefer postponed retirement with a replacement rate of $90 \%$ to benchmark. With increasing replacement rates, the number of people choosing postponed retirement increases, but even with a replacement rate of $110 \%$ (a compensation for late retirement that is more than actuarially fair), only $11 \%$ of all respondents would opt for late retirement. ${ }^{9}$ The final three columns give the choice probabilities by age group. Particularly in the age groups 45-64 very few respondents would choose late retirement.

Scenarios, Early 1, 2 and 3 describe early retirement at age 62 with replacement rates equal to 50, 60 and $70 \%$ of net pre-retirement earnings. Scenario Early 1 is preferred to the benchmark by $13 \%$ of the respondents. An increase in the replacement rate substantially increases the attractiveness of early retirement: scenario Early 2 with replacement rate $60 \%$ is already preferred to the benchmark by more than a quarter of the respondents, and scenario Early 3 with replacement rate $70 \%$ is preferred to the benchmark scenario by $57 \%$ of all respondents. The annual incomes in this scenario differ from those of the benchmark scenario only during the period from age 62 to age 65 . The utility of being fully retired compared to being at work at these ages compensates the decrease in utility due to the lower income during early retirement. Particularly in the age group 45-64, many respondents would be willing to pay this rather low (and actuarially less than fair) price for early retirement.

\footnotetext{
${ }^{9}$ The benchmark with retirement age 65 and replacement rate $70 \%$ is actuarially equivalent to late retirement at age 70 and replacement rate $103 \%$; see also Table 7 and its discussion.
} 
Table 6: Probabilities of Choosing Described Trajectory rather than Benchmark

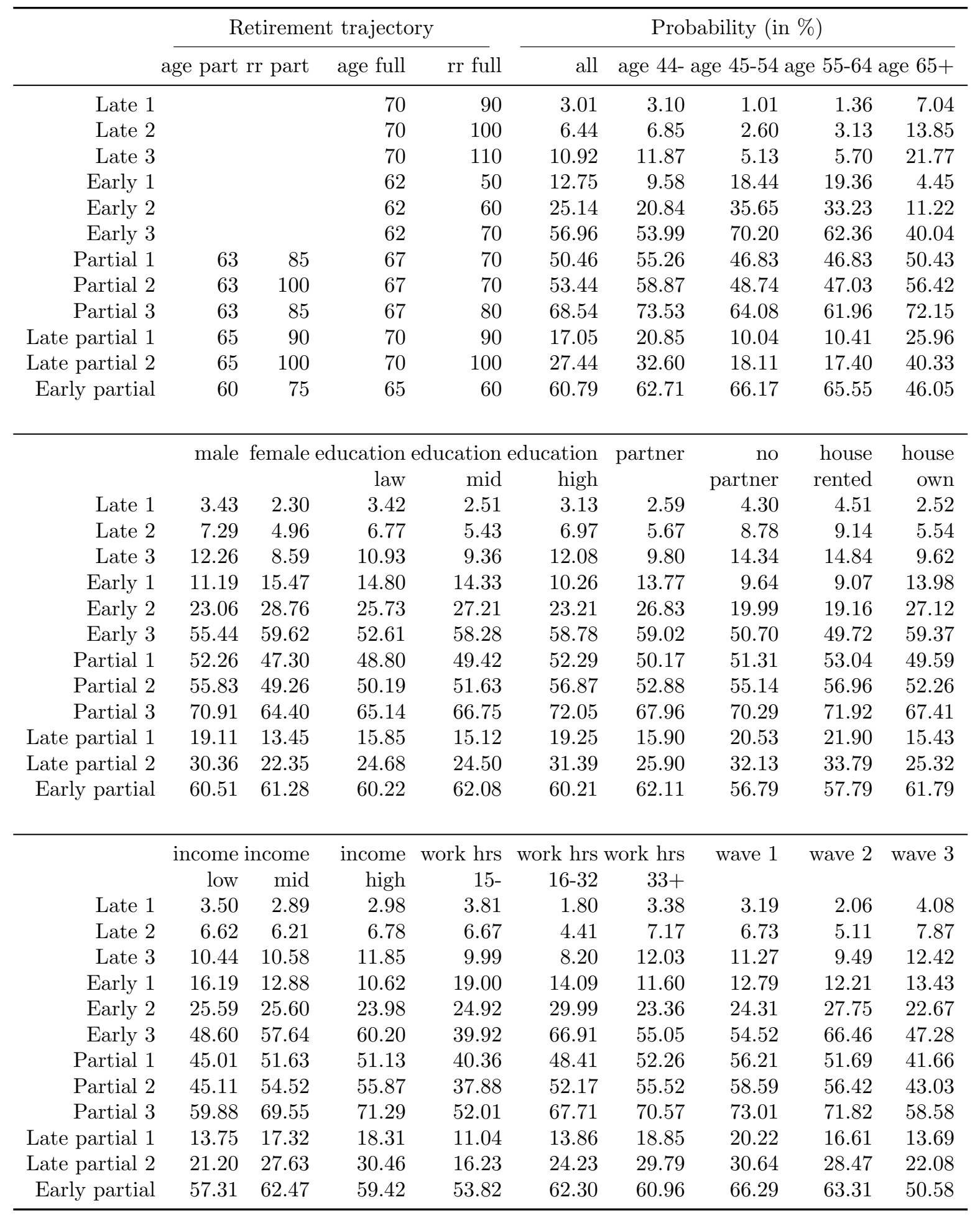


The last six scenarios, Partial 1 to Early partial, involve gradual retirement. Partial 1, 2 and 3 have partial retirement at age 63 and full retirement at age 67, with three different replacement rates. On average, respondents appear to be indifferent between Partial 1 and the benchmark. An increase in the replacement rate during partial retirement (Partial 2, by 15\%-points) or full retirement (Partial 3 , by $10 \%$-points) makes gradual retirement more attractive, but the effect is much stronger in the latter case. This is mainly a consequence of the negative estimate of $\alpha^{p y}$ which reduces the importance of the replacement rate during partial retirement compared to that during full retirement.

In scenarios Late partial 1 and 2, the partial retirement age is 65 and the full retirement age is 70 - the same age as in Late 1, 2 and 3. Scenario Late partial 1 offers a $20 \%$-points higher replacement rate than the benchmark in return for working $60 \%$ of the pre-retirement working week for five years. This scenario is found more attractive than the benchmark scenario by $17 \%$ of the sample, mainly in the youngest and oldest age cohorts. Late partial 2 increases the replacement rates by 10\%-points compared to Late partial 1. Accordingly, the fraction of people preferring this scenario to the benchmark rises to $27 \%$. These fractions are much higher than the fractions preferring to work until age 70 without gradual retirement. Almost no-one wants to work their full pre-retirement hours till age 70, but many more people are willing to work a reduced number of hours until this age.

Finally, the scenario Early partial offers partial retirement at age 60 and full retirement at age 65 . About $60 \%$ of the respondents prefer this to the benchmark, although the corresponding pension income is lower than what would be actuarially fair. For many respondents, the early partial retirement scenario is apparently also more attractive than scenario Early 2, which gives the same replacement rate after age 65 but has immediate full retirement at age 62 . This shows that early and late gradual retirement may be attractive alternatives for early and late full retirement. Early gradual retirement is particularly attractive for the age group 54-64, while the youngest and oldest age groups often prefer late gradual retirement.

The results for the complete sample can be compared with those of Van Soest et al. (2006, Table 9, final column $)^{10}$ who used a similar methodology with older data and a less flexible model. Most results are qualitatively similar though we find a smaller tendency to choose the gradual retirement scenarios. Moreover, we find an even smaller effect of increasing the replacement rate during partial retirement,

\footnotetext{
${ }^{10}$ Since Van Soest et al. (2006) cannot estimate the noise level in choice questions, they use either the noise level in ratings or noise level zero in their simulations. Our results are better comparable to the latter case (final column in their Table 9), since our estimates imply that the noise level in choices is much smaller than in ratings.
} 
in line with our negative estimate of $\alpha^{p y}$.

In the second and third panel of Table 6, we present simulated choice probabilities for various subsamples of respondents characterized by background characteristics other than age. The differences between groups are generally smaller than the differences between age groups in the top panel. Women have somewhat lower preferences for late retirement trajectories and higher preferences for early retirement trajectories than men. They also seem to be less interested in gradual retirement. Preferences for early or late retirement hardly vary with education level, but the higher educated have a stronger preference for gradual retirement than other educational groups. Respondents living with a partner have a stronger preference for all forms of early retirement and an accordingly larger distaste for late retirement than respondents not living with a partner. The same applies to home owners versus renters. The choices of the high income groups are more sensitive to the replacement rate than those of lower income groups, particularly when it comes to early retirement. Higher income respondents are also more interested in gradual retirement. Full-time workers have the largest tendency to choose late gradual retirement, while part-timers (working 16-32 hours per week) have the strongest preference for early retirement or early gradual retirement. Comparing the simulated probabilities over the years of the data collection, we find that the attractiveness of all gradual retirement scenarios is falling over time. This can also explain why we find fewer choices of gradual retirement than Van Soest et al. (2006). In 2008, we also find a substantially smaller tendency to choose early retirement and a somewhat increased tendency to choose late retirement. These results may reflect changing social norms.

\subsection{Choice of Retirement Age}

Table 7 considers the choice between the benchmark (retirement at age 65; replacement rate $70 \%$ ) and a scenario that is actuarially equivalent ${ }^{11}$ to the benchmark but has a different retirement age. Gradual retirement is not considered here. The actuarially fair replacement rates (in the second column) are taken from Queisser and Whitehouse (2006), on the basis of a $2 \%$ interest rate, average life expectancy for OECD countries, and price indexation of pensions.

\footnotetext{
${ }^{11}$ Actuarial neutrality of pension trajectories requires that the present value of accrued pension benefits for working an additional year is the same as in the year before. See Queisser and Whitehouse (2006) for a discussion of actuarial neutrality and related concepts.
} 
Table 7: Probability of Choosing Actuarially Neutral Alternative rather than Benchmark Trajectory

\begin{tabular}{rrr}
\hline age & $\begin{array}{r}\text { rr -actuar. } \\
\text { neutral }\end{array}$ & $\begin{array}{r}\text { probability } \\
\text { (in \%) }\end{array}$ \\
\hline 60 & 50.26 & 5.49 \\
61 & 53.45 & 10.93 \\
62 & 56.95 & 19.83 \\
63 & 60.80 & 32.10 \\
64 & 65.14 & 44.51 \\
65 & 70.00 & 50.00 \\
66 & 75.00 & 44.62 \\
67 & 81.16 & 35.05 \\
68 & 87.71 & 23.80 \\
69 & 95.17 & 14.52 \\
70 & 103.53 & 7.93 \\
\hline
\end{tabular}

Note: Acturial neutral retirement scenarios taken from Queisser and Whitehouse (2006). They are calculated for the OECD average based on a $2 \%$ interest rate, average life expectancy for OECD countries, and price indexation of pensions.

Like the previous table, the table presents the simulated probabilities of choosing full retirement at the alternative age (third column). For example $19.8 \%$ of all people would prefer to retire at age 62 with a replacement rate of about $57 \%$ rather than at age 65 with replacement rate $70 \%$. The simulated probabilities show that most people prefer standard retirement at age 65 to actuarially equivalent early as well as late retirement.

In the remaining simulations we consider the choice between 11 options: retirement at age $60,61, \ldots, 69$ or 70 , without any opportunities for gradual retirement, and for a variety of (retirement age dependent) replacement rates. The baseline case is the set of 11 actuarially equivalent scenarios already presented in Table 7, but instead of comparing each of these scenarios with the benchmark, we now consider the choice between all 11 scenarios. Column "rr" of Table 8 presents the probability of each choice averaged over the complete sample, as well as the corresponding average retirement age for this baseline case. ${ }^{12}$ The mode is 65 years and the mean desired retirement age is 65.08 years, corresponding to the symmetry we already found in Table 7. Still there is also substantial dispersion, with, for example, more than $20 \%$ choosing to retire at age 63 or earlier, and more than $23 \%$ opting for retirement at

\footnotetext{
${ }^{12}$ Both the unobserved heterogeneity terms and the optimization errors are taken into account.
} 
age 67 or later.

Table 8: Income Effect on Preferred Retirement Age

\begin{tabular}{lrrrrrrr}
\hline \multirow{2}{*}{ age } & \multicolumn{6}{c}{ prob. distribution of preferred retirement age (in \%) } \\
\cline { 2 - 8 } & $\mathrm{rr}$ & $0.7 \mathrm{rr}$ & $0.8 \mathrm{rr}$ & $0.9 \mathrm{rr}$ & $1.1 \mathrm{rr}$ & $1.2 \mathrm{rr}$ & $1.3 \mathrm{rr}$ \\
\hline 60 & 0.83 & 0.94 & 0.89 & 0.85 & 0.81 & 0.80 & 0.80 \\
61 & 2.32 & 1.87 & 2.00 & 2.15 & 2.54 & 2.78 & 3.08 \\
62 & 5.77 & 3.83 & 4.39 & 5.03 & 6.62 & 7.60 & 8.71 \\
63 & 11.38 & 7.12 & 8.39 & 9.81 & 13.10 & 14.95 & 16.90 \\
64 & 17.59 & 11.50 & 13.48 & 15.53 & 19.59 & 21.43 & 23.01 \\
65 & 20.97 & 15.78 & 17.80 & 19.57 & 21.90 & 22.34 & 22.32 \\
66 & 17.88 & 17.04 & 17.88 & 18.15 & 17.10 & 15.92 & 14.45 \\
67 & 12.84 & 16.49 & 15.73 & 14.46 & 11.02 & 9.19 & 7.44 \\
68 & 6.78 & 12.71 & 10.73 & 8.70 & 5.10 & 3.69 & 2.57 \\
69 & 2.78 & 8.26 & 6.00 & 4.18 & 1.77 & 1.08 & 0.62 \\
70 & 0.86 & 4.47 & 2.71 & 1.57 & 0.44 & 0.21 & 0.10 \\
\hline mean age (years) & 65.08 & 65.95 & 65.63 & 65.35 & 64.83 & 64.61 & 64.41 \\
difference (months) & 0 & 10.44 & 6.60 & 3.24 & -3.00 & -5.64 & -8.04 \\
\hline
\end{tabular}

Note: In this table we change the pension wealth in actuarially neutral trajectories and study its impact on the mean age. In column "rr" we let people choose between all eleven scenarios with full retirement at ages 60 to 70 and replacement rates in Table 7 . In columns "1.1 rr", "1.2 rr" and "1.3 rr" we increase these replacement rates by $10 \%$, $20 \%$ and $30 \%$, respectively. In columns "0.9 rr", "0.8 rr" and "0.7 rr" we decrease these replacement rates as indicated. In each column, we give the probability distributions of preferred retirement age, the mean retirement age measured in years and the difference between this and the mean retirement age and the baseline choice set "rr".

The other columns of the table give insight in the "(pension) income effect" on the preferred retirement age, i.e. how does the preferred retirement age change if the total value of life-time pension income changes, irrespective of the retirement age. To compute it, we increased or decreased the replacement rates in all 11 scenarios by a fixed percentage - 10, 20 or $30 \%$ - and calculated the simulated probabilities for each new choice set. These simulated probabilities are presented in the other columns of Table 8 , labeled " $0.7 \mathrm{rr}$ " (replacement rates reduced by $30 \%$ ), "0.8 rr",.., "1.3 rr".

An increase in the replacement rates makes early retirement more attractive and makes late retirement less attractive: in columns " $1.1 \mathrm{rr}$ ", "1.2 rr" and "1.3 rr" we observe a gradual increase of early retirement choices and a decrease of late 
Figure 2: Income Effect on the Preferred Retirement Age - Probability distribution of preferred retirement ages for varying replacement rates (cf. Table 8)

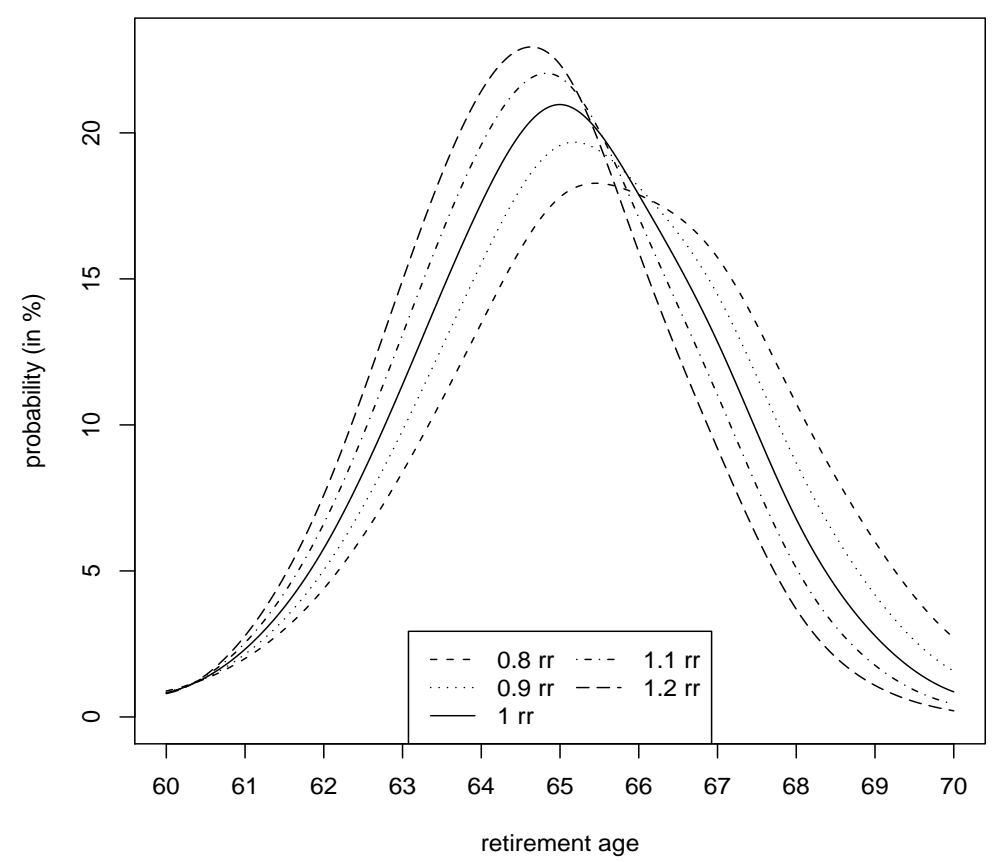

retirement choices. For example, the probability to retire at age 63 or earlier rises from $20.3 \%$ in the baseline case ("rr") to $29.3 \%$ when all pension incomes would be raised by $30 \%$. At the same time, the percentage retiring at age 67 or later would fall from $23.3 \%$ to $10.7 \%$. For the lower replacement rates (columns "0.9 rr", "0.8 rr" and "0.7 rr") we observe the opposite trend. A graphical illustration of these shifts in probability distributions for changing pension incomes is presented in Figure 2. These changes can be seen as pure income effects, since the accruals, i.e., the rewards for retiring earlier or later, do not change (in relative terms), implying that the substitution effects are zero. The implied results for the average retirement age show that the income effects are of the expected negative sign and substantial: a $10 \%$ increase in all replacement rates would, for example, reduce the average age of preferred retirement by three months (see the bottom rows of the table).

The income effect can be compared with the "pension wealth" effect found by Euwals et al. (2007) who analyze preferences for early retirement of Dutch public sector employees, using administrative data from the main public sector pension fund. They find that reducing pension wealth by 100,000 euros would induce the average worker to postpone retirement by 5 or 6 months (p.21). The lump sum 
of 100,000 euros corresponds to an annuity of about $25 \%$ of average pre-retirement earnings and is therefore similar to an increase of the replacement rate by somewhat more than $30 \%$. According to our estimates, this would raise the average retirement age by more than 8 months, which is larger than the result of Euwals et al. This is not so surprising since we look at desired retirement instead of actual retirement and allow for quite flexible choices (any retirement age from age 60 to 70), while the literature provides evidence that retirement choices are often much more restricted and certainly in the Netherlands, actual opportunities for retiring after age 65 are scarce (cf., e.g, Van Solinge and Henkens (2007)).

With some additional assumptions, we can also roughly compare these income effects with the "wealth effects" found by Brown et al. (2006) who look at the effect of (expected and unexpected) inheritances on retirement using the US Health and Retirement Study. One of their dependent variables is the two-year (i.e., wave to wave) retirement rate, with a sample average of $19.2 \%$ (Table 5 in Brown et al.). They find that a $\$ 100,000$ inheritance increases this rate by about $2.1 \%$ points. To compare this with our findings, we consider the retirement rate at age 62 or age 63 , which is $17.7 \%$ in our baseline case with actuarially fair trade offs $((5.77+11.38) /(100-0.83-2.32)$, see Table 8). A $\$ 100,000$ lump sum transfer at age 62 would roughly correspond to an annuity of about 15 to $20 \%$ of average annual preretirement earnings. The retirement rate at age 62 or 63 for this higher replacement rate can be derived from the columns " $1.2 \mathrm{rr}$ " and is about $22.6 \%, 4.9 \%$-points higher than in the baseline case. This is much larger than the $2.1 \%$ found by Brown et al. Note, however, that in their later analysis, Brown et al. find larger effects of unexpected inheritances than of expected inheritances, a distinction not made for this particular estimate, and our estimate probably corresponds more to the effect of an unexpected inheritance ${ }^{13}$.

In Table 9 we present the income effects on the mean preferred retirement age for different socioeconomic groups. The first column concerns the baseline case. The main differences across socio-economic groups here are the age differences: the age groups 45-64 prefer to retire earlier than the younger and older age groups. The other columns present the income effects in terms of changes (in months) of the average preferred retirement age, computed in the same way as in the bottom row of Table 8. The sign of the income effect is the same for all subgroups, but there is

\footnotetext{
${ }^{13}$ We cannot compare our estimates to these later estimates of Brown et al., since these use the dependent variable "retiring earlier than expected" which we cannot construct. Substantial negative income effects for Dutch workers are also implied by the simulation results of Mastrogiacomo et al. (2004, p.790); the magnitude of these effects is not comparable to our estimates since they look at changes in pre-retirement wages.
} 
some variation in magnitude. For example, the income effects increase with socioeconomic status (education level and income) and are relatively small for workers with a small part-time job.

Table 9: Income Effects on Mean Preferred Retirement Age by Socioeconomic Group

\begin{tabular}{lrrrrrrr}
\hline & \multicolumn{7}{c}{ retirement age } \\
\cline { 2 - 7 } & $\mathrm{rr}$ & $0.7 \mathrm{rr}$ & $0.8 \mathrm{rr}$ & $0.9 \mathrm{rr}$ & $1.1 \mathrm{rr}$ & $1.2 \mathrm{rr}$ & $1.3 \mathrm{rr}$ \\
\hline all & 65.08 & 10.44 & 6.60 & 3.24 & -3.00 & -5.64 & -8.04 \\
age 44- & 65.28 & 10.80 & 6.92 & 3.33 & -3.06 & -5.88 & -8.50 \\
age 45-54 & 64.52 & 9.96 & 6.31 & 3.01 & -2.74 & -5.25 & -7.57 \\
age 55-64 & 64.59 & 8.74 & 5.55 & 2.63 & -2.41 & -4.62 & -6.66 \\
age 65+ & 65.93 & 11.40 & 7.40 & 3.60 & -3.39 & -6.55 & -9.47 \\
male & 65.20 & 10.64 & 6.82 & 3.28 & -3.03 & -5.82 & -8.41 \\
female & 64.86 & 9.70 & 6.18 & 2.95 & -2.71 & -5.22 & -7.53 \\
education low & 65.04 & 9.20 & 5.89 & 2.83 & -2.61 & -5.02 & -7.25 \\
education mid & 64.94 & 9.89 & 6.31 & 3.02 & -2.77 & -5.31 & -7.67 \\
education high & 65.21 & 11.30 & 7.24 & 3.48 & -3.22 & -6.19 & -8.94 \\
partner & 64.98 & 10.18 & 6.50 & 3.12 & -2.87 & -5.51 & -7.95 \\
no partner & 65.38 & 10.65 & 6.84 & 3.29 & -3.05 & -5.88 & -8.50 \\
house rented & 65.44 & 10.73 & 6.90 & 3.33 & -3.10 & -5.95 & -8.60 \\
house own & 64.96 & 10.15 & 6.48 & 3.10 & -2.85 & -5.48 & -7.92 \\
income low & 65.01 & 8.23 & 5.25 & 2.52 & -2.34 & -4.48 & -6.48 \\
income mid & 65.05 & 10.30 & 6.59 & 3.16 & -2.90 & -5.58 & -8.06 \\
income high & 65.18 & 11.42 & 7.31 & 3.51 & -3.25 & -6.25 & -9.03 \\
working hours 15- & 64.97 & 6.33 & 4.04 & 1.93 & -1.78 & -3.40 & -4.95 \\
working hours 16-32 & 64.83 & 10.98 & 7.01 & 3.35 & -3.07 & -5.91 & -8.51 \\
working hours 33+ & 65.18 & 10.46 & 6.69 & 3.22 & -2.97 & -5.72 & -8.26 \\
wave 1 & 65.11 & 10.01 & 6.41 & 3.07 & -2.83 & -5.46 & -7.87 \\
wave 2 & 64.97 & 11.54 & 7.37 & 3.53 & -3.25 & -6.24 & -9.01 \\
wave 3 & 65.19 & 8.99 & 5.76 & 2.77 & -2.56 & -4.92 & -7.12 \\
\hline
\end{tabular}

Note: Income effects are calculated as in Table 8. In column "rr", we let the given group choose between all eleven scenarios with full retirement at ages from 60 to 70 and replacement rates "rr" from Table 7 . We present the mean preferred retirement age (in years) by group. In other columns we change the replacement rates as indicated and calculate the differences (in months) between the new mean and the mean in the baseline (column "rr"). The differences in the row "all" correspond to the differences in Table 8. 
Substitution effects on the retirement age are presented in Table 10. The baseline (column "rr") is the same as in Table 8. The alternatives do not change generosity of pensions when retiring at age 65 , but increase or decrease the accruals, i.e., the rewards for retiring later or the penalty for retiring earlier, giving "flatter" or "steeper" relationships between the retirement age and the replacement rate. To be precise, the new replacement rates are equal to $70+x(r r-70)$, where $r r$ are the replacement rates in the actuarially neutral scenarios (Table 7), 70 is the replacement rate in the benchmark scenario with retirement age 65 and $x$ is a multiplication factor. For example for $x=0.5$ the new replacement rate when retiring at age 60 is equal to $70+0.5(50.26-70)=60.13 \%$, for retirement age 61 it is $70+0.5 *$ $(53.45-70)=61.73 \%$, etc. If $x$ is equal to 1 , the replacement rates are those of the baseline case with actuarially equivalent trajectories. If $0 \leq x<1$, the accruals are negative and early retirement scenarios become financially more attractive. If $x>1$, accruals are positive, implying a stronger financial incentive to retire later. In our simulation, we consider $x$ equal to $0,0.33,0.5,1,2$ and 3 . In the extreme case, $x=0$, the replacement rate is equal to 70 irrespective of the retirement age.

In the baseline choice set "rr", people on average prefer to retire at age 65.1, as we saw before. With the positive accruals in column "70+2(rr-70)", the average retirement age would increase by almost one year, since later retirement is made more attractive. For example, the percentage preferring to retire at age 67 or later would increase from $23.3 \%$ to $44.9 \%$, while the percentage wanting to retire at age 63 or earlier would drop from $20.3 \%$ to $10.3 \%$. On the other hand, if the accruals are reduced so much that the only "penalty" for retiring early is a lower income during the years of early retirement (column "70"), the average retirement age would fall by almost 1.75 years, with about $56 \%$ wanting to retire at age 63 or earlier. The main reason why many respondents do not choose to retire even earlier according to our model estimations is the effect of age on utility when retired, which implies that, keeping income constant, for many respondents retirement is less attractive than pre-retirement at age 60 or 61 . 
Table 10: Substitution Effect on the Preferred Retirement Age

\begin{tabular}{lrrrrrrr}
\hline \multirow{2}{*}{ age } & \multicolumn{7}{c}{ Distribution of preferred retirement age (in \%) } \\
\cline { 2 - 8 } & \multicolumn{1}{c}{ rr } & 70 & $70+0.33(\mathrm{rr}-70)$ & $70+0.5(\mathrm{rr}-70)$ & $70+2(\mathrm{rr}-70)$ & $70+3(\mathrm{rr}-70)$ & 90,70 \\
\hline 60 & 0.83 & 1.69 & 0.97 & 0.85 & 1.35 & 2.39 & 5.09 \\
61 & 2.32 & 8.50 & 4.82 & 3.80 & 1.45 & 0.80 & 17.25 \\
62 & 5.77 & 19.72 & 12.98 & 10.44 & 2.54 & 1.30 & 27.48 \\
63 & 11.38 & 26.21 & 21.38 & 18.52 & 5.00 & 2.69 & 25.63 \\
64 & 17.59 & 22.62 & 23.61 & 22.69 & 9.51 & 5.75 & 15.34 \\
65 & 20.97 & 13.50 & 18.73 & 20.26 & 15.97 & 11.71 & 5.98 \\
66 & 17.88 & 5.67 & 10.69 & 13.08 & 19.23 & 17.47 & 2.39 \\
67 & 12.84 & 1.69 & 4.78 & 6.78 & 20.16 & 23.07 & 0.68 \\
68 & 6.78 & 0.35 & 1.57 & 2.61 & 14.37 & 19.27 & 0.14 \\
69 & 2.78 & 0.05 & 0.40 & 0.78 & 7.59 & 11.25 & 0.02 \\
70 & 0.86 & 0.00 & 0.08 & 0.18 & 2.82 & 4.31 & 0.00 \\
\hline mean age (years) & 65.08 & 63.34 & 63.98 & 64.27 & 66.07 & 66.58 & 62.61 \\
difference (months) & 0.00 & -20.88 & -13.20 & -9.72 & 11.88 & $18.00-29.64$ \\
\hline
\end{tabular}

Note: In column "rr", we let people choose between eleven actuarially equivalent scenarios with full retirement at ages from 60 to 70 and replacement rates "rr" in Table 7 . In other columns labeled "70+x(rr-70)", we change replacement rates as indicated (see the text for an example). In column "90,70", the replacement rates are all equal to 90 till age 65 and 70 from age 65 . In each column, we give the probability distribution of the preferred retirement age, the mean retirement age (in years) and its difference (in months) with the mean retirement age for the baseline choice set "rr".

The substitution effect can be compared with the "price effect" of Euwals et al. (2007) who find that increasing the peak value by 100,000 euros would induce a worker to postpone retirement by about 8 months. Changing from column "rr" to column "70+3(rr-70)" increases the reward for postponing retirement in terms of pension income per year at age 65 from 5\%-points to 15\%-points of pre-retirement earnings, corresponding to a change in peak value (defined as the increase in lifetime wealth if the worker decides to continue working for one year) of about 40,000 euros for the average worker. Our estimates would imply that this increases the average retirement age by 18 months. The substitution effect we find is therefore much larger than the effect found by Euwals et al. (2007). As for the income effect, a plausible explanation for the difference is that we look at desired retirement allowing for maximum flexibility - each age between 60 and 70 is possible, whereas Euwals 
et al. (2007) consider actual retirement, which may also be affected by implicit or explicit restrictions imposed by the employer like mandatory retirement at age 65 .

The final column of Table 10 (column "90,70") shows the response to an arrangement that mimics a stylized version of the generous early retirement arrangements in the Netherlands and other countries as they existed in the nineties: a fixed replacement rate of $70 \%$ after age 65 (irrespective of the retirement age), and a replacement rate of $90 \%$ between early retirement and age 65 (irrespective of the early retirement age). As expected, this makes early retirement even more attractive than the arrangement which also gives a replacement rate of $70 \%$ in the years between early retirement and age 65 . More than $75 \%$ would prefer to retire at age 63 or earlier, and almost $50 \%$ of the respondents would choose retirement at age 62 or earlier. Retirement at age 60 remains uncommon, because of the estimated negative utility of retirement at this age. The average retirement age would drop by almost 30 months compared to the baseline choice set with actuarially equivalent choices. This estimate fits in the range of estimates given by Kapteyn and De Vos (2004, p. 493) who simulate a "common reform" from the actual system with generous early retirement opportunities to an approximately actuarially fair system with retirement between age 60 and age 65. Depending on their model specification, they find smaller or larger effects than we do. Again, we would expect to find larger effects than Kapteyn et al. (2004) because we also allow for retirement beyond age 65 .

Table 11, presents the substitution effect for various socioeconomic groups. The first column is the same as in Tabls 9, giving the average preferred retirement age for the baseline of actuarially fair choices. The other columns show the substitution effects expressed as the number of months the average preferred retirement age by subgroup changes when the rewards for retiring later increase or decrease (as in the final row of Table 10). The results are comparable to those in Table 9: the groups with the higher income effects also have the higher substitution effects (high income, high education level). The group of respondents with a small part-time job generally seems less sensitive to financial incentives than all other groups. 
Table 11: Substitution Effect on the Mean Preferred Retirement Age by Socioeconomic Group

\begin{tabular}{lrrrrrrr}
\hline & \multicolumn{7}{c}{ retirement age } \\
\cline { 2 - 7 } & rr & \multicolumn{7}{c}{$7070+0.33(\mathrm{rr}-70)$} & $70+0.5(\mathrm{rr}-70)$ & $70+2(\mathrm{rr}-70)$ & $70+3(\mathrm{rr}-70)$ & 90,70 \\
\hline all & 65.08 & -20.88 & -13.20 & -9.72 & 11.88 & 18.00 & -29.64 \\
age 44- & 65.28 & -21.86 & -13.85 & -9.93 & 12.25 & 18.30 & -31.20 \\
age 45-54 & 64.52 & -20.25 & -13.15 & -9.54 & 12.77 & 19.55 & -28.44 \\
age 55-64 & 64.59 & -17.37 & -11.23 & -8.14 & 10.94 & 16.81 & -24.48 \\
age 65+ & 65.93 & -23.65 & -14.66 & -10.37 & 11.73 & 17.14 & -33.72 \\
male & 65.20 & -21.67 & -13.75 & -9.85 & 12.23 & 18.33 & -30.84 \\
female & 64.86 & -19.60 & -12.55 & -9.05 & 11.65 & 17.65 & -27.60 \\
education low & 65.04 & -18.46 & -11.74 & -8.44 & 10.74 & 16.25 & -26.04 \\
education mid & 64.94 & -19.90 & -12.72 & -9.15 & 11.80 & 17.88 & -28.08 \\
education high & 65.21 & -23.24 & -14.76 & -10.58 & 13.00 & 19.41 & -33.12 \\
partner & 64.98 & -20.66 & -13.19 & -9.49 & 12.06 & 18.21 & -29.28 \\
no partner & 65.38 & -21.68 & -13.67 & -9.77 & 11.88 & 17.69 & -30.84 \\
house rented & 65.44 & -21.88 & -13.77 & -9.83 & 11.87 & 17.66 & -31.08 \\
house own & 64.96 & -20.59 & -13.16 & -9.47 & 12.06 & 18.22 & -29.16 \\
income low & 65.01 & -16.29 & -10.33 & -7.43 & 9.46 & 14.30 & -22.80 \\
income mid & 65.05 & -20.85 & -13.30 & -9.55 & 12.12 & 18.30 & -29.64 \\
income high & 65.18 & -23.55 & -14.96 & -10.74 & 13.21 & 19.73 & -33.60 \\
work hrs 15- & 64.97 & -12.03 & -7.58 & -5.41 & 6.85 & 10.21 & -16.44 \\
work hrs 16-32 & 64.83 & -22.54 & -14.49 & -10.44 & 13.39 & 20.23 & -31.92 \\
work hrs 33+ & 65.18 & -21.23 & -13.47 & -9.66 & 12.05 & 18.11 & -30.12 \\
wave 1 & 65.11 & -20.16 & -12.81 & -9.20 & 11.60 & 17.48 & -28.68 \\
wave 2 & 64.97 & -23.90 & -15.28 & -11.00 & 13.76 & 20.65 & -33.96 \\
wave 3 & 65.19 & -17.85 & -11.29 & -8.09 & 10.20 & 15.39 & -25.20 \\
\hline & & & & & & &
\end{tabular}

Note: Substitution effects are calculated as in Table 10. In column "rr", the choices are between all eleven scenarios with full retirement at ages from 60 to 70 and replacement rates "rr" from Table 7 . We present the mean preferred retirement age (in years) by group. In other columns replacement rates imply positive or negative accruals as indicated, and the differences (in months) between the new mean and the mean in the baseline (column "rr") is presented. The differences in the row "all" correspond to those in Table 10.

\section{Sensitivity Analysis}

In this section, we investigate the sensitivity of the simulated income and substitution effects presented in Tables 8 and 10 on the preferred retirement age for some of the specification choices made in our model. We compare the results of the bench- 
mark model, from now on referred to as $M 0$, to those of five alternative models, named $M 1, M 2, M 3, M 4$ and $M 5$. The estimated income effects are presented in Table 12, and Table 13 presents the substitution effects.

Table 12: Sensitivity Analysis Income Effect on Preferred Retirement Age

\begin{tabular}{llrrrrrrr}
\hline & & \multicolumn{7}{c}{ retirement age } \\
\cline { 3 - 9 } & & $\mathrm{rr}$ & $0.7 \mathrm{rr}$ & $0.8 \mathrm{rr}$ & $0.9 \mathrm{rr}$ & $1.1 \mathrm{rr}$ & $1.2 \mathrm{rr}$ & $1.3 \mathrm{rr}$ \\
\hline M0 & mean & 65.08 & 65.95 & 65.63 & 65.35 & 64.83 & 64.61 & 64.41 \\
& dif & 0.00 & 10.44 & 6.60 & 3.24 & -3.00 & -5.64 & -8.04 \\
M1 & mean & 65.11 & 65.80 & 65.56 & 65.33 & 64.91 & 64.72 & 64.53 \\
& dif & 0.00 & 8.25 & 5.34 & 2.61 & -2.45 & -4.71 & -6.99 \\
M2 & mean & 65.09 & 65.92 & 65.62 & 65.32 & 64.86 & 64.63 & 64.43 \\
& dif & 0.00 & 10.03 & 6.41 & 2.83 & -2.76 & -5.54 & -7.96 \\
M3 & mean & 65.08 & 65.93 & 65.62 & 65.36 & 64.84 & 64.64 & 64.43 \\
& dif & 0.00 & 10.14 & 6.52 & 3.31 & -2.85 & -5.23 & -7.81 \\
M4 & mean & 65.29 & 65.72 & 65.55 & 65.42 & 65.16 & 65.07 & 64.95 \\
& dif & 0.00 & 5.16 & 3.12 & 1.50 & -1.61 & -2.71 & -4.11 \\
M5 & mean & 64.96 & 66.07 & 65.67 & 65.31 & 64.64 & 64.34 & 64.07 \\
& dif & 0.00 & 13.35 & 8.55 & 4.17 & -3.88 & -7.42 & -10.74 \\
\hline
\end{tabular}

Note: M0 - benchmark model of Section 3; M1 - M0 with term $\alpha^{y^{2}}\left(y_{i s t}\right)^{2}$ added to right hand side in eq. 2; M2 - M0 but observed characteristics $X_{i s}$ are just sex and age; M3 - M0 but observed characteristics $X_{i s}$ are just sex, age, education and partner; M4 - M0 with fixed discount factor $\rho=0.95$; M5 - M0 with fixed discount factor $\rho=0.85$.

Model $M 1$ extends the benchmark model by adding a quadratic term $\alpha^{y^{2}} y_{i s t}^{2}$ to the right hand side of equation 2. Differences in the simulated income effects and substitution effects calculated using model $M 1$ and the benchmark model $M 0$ are small. The estimated parameter $\alpha^{y^{2}}$ is not significantly different from zero. It demonstrates that extending the benchmark model with a quadratic term of log income neither leads to a better fit nor to different conclusions.

Models $M 2$ and $M 3$ are simplified versions of the benchmark model M0. They both incorporate fewer observed characteristics $X_{i s}$ than $M 0$. Model $M 2$ uses just sex and age of the respondents while model $M 3$ includes sex, age, education and partnership status. Compared to Model M0, M3 drops income, number of paid working hours and home ownership, variables which might be determined by the same unobserved characteristics that drive the tastes for work versus leisure and therefore also retirement preferences, so that their effects are not necessarily causal. As shown in Tables 12 and 13, the differences in the simulated income and substitu- 
tion effects of models $M 0, M 2$ and $M 3$ are negligible, demonstrating the robustness of our results for including these variables that are in a sense potentially endogenous.

Table 13: Sensitivity Analysis Substitution Effect on Preferred Retirement Age

\begin{tabular}{llrrrrrrr}
\hline & \multicolumn{7}{c}{ retirement age } \\
\cline { 3 - 9 } & & rr & 70 & $70+0.33(\mathrm{rr}-70)$ & $70+0.5(\mathrm{rr}-70)$ & $70+2(\mathrm{rr}-70)$ & $70+3(\mathrm{rr}-70)$ & 90,70 \\
\hline \multirow{2}{*}{ M0 } & mean & 65.08 & 63.34 & 63.98 & 64.27 & 66.07 & 66.58 & 62.61 \\
& dif & 0.00 & -20.88 & -13.20 & -9.72 & 11.88 & 18.00 & -29.64 \\
M1 & mean & 65.11 & 63.38 & 64.02 & 64.33 & 66.14 & 66.61 & 62.64 \\
& dif & 0.00 & -20.73 & -13.11 & -9.40 & 12.39 & 18.05 & -29.67 \\
M2 & mean & 65.09 & 63.37 & 64.01 & 64.31 & 66.08 & 66.60 & 62.66 \\
& dif & 0.00 & -20.59 & -12.88 & -9.25 & 12.00 & 18.20 & -29.14 \\
M3 & mean & 65.08 & 63.36 & 63.97 & 64.29 & 66.09 & 66.59 & 62.65 \\
& dif & 0.00 & -20.67 & -13.27 & -9.46 & 12.06 & 18.08 & -29.20 \\
M4 & mean & 65.29 & 63.71 & 64.26 & 64.53 & 66.28 & 66.78 & 63.41 \\
& dif & 0.00 & -18.96 & -12.36 & -9.12 & 11.88 & 17.88 & -22.56 \\
M5 & mean & 64.96 & 63.15 & 63.84 & 64.15 & 65.94 & 66.45 & 62.10 \\
& dif & 0.00 & -21.78 & -13.47 & -9.70 & 11.74 & 17.86 & -34.29 \\
\hline
\end{tabular}

Note: M0 - benchmark model of Section 3; M1 - M0 with term $\alpha^{y^{2}}\left(y_{i s t}\right)^{2}$ added to right hand side in eq. 2; M2 - M0 but observed characteristics in $X_{i s}$ are just sex and age; M3 - M0 but observed characteristics $X_{i s}$ are just sex, age, education and partner; M4 - M0 with fixed discount factor $\rho=0.95$; M5 - M0 with fixed discount factor $\rho=0.85$.

Finally, we consider two models in which the discount rate is fixed to a given value rather than estimated. The discount rate appeared to be numerically the hardest parameter to estimate - with a fixed discount rate, estimating the model appeared to be much faster than when also estimating the discount rate. This is why we wanted to investigate the consequences of setting the discount rate to a specific value. In the benchmark model $M 0$ the estimated discount factor is $\rho=0.89$. In models $M 4$ and $M 5$ we set the discount factor to 0.95 and 0.85 , respectively. The results in Table 12 show that the income effects crucially depend on the discount rate. Setting the discount rate to a very low value (0.85, model M5) leads to much larger estimates of the income elasticities than setting it to a higher value $(0.95$, model M4) - in the latter model, the estimates are less than half as large as the estimates in the former model. The benchmark model with its estimated discount rate of 0.90 gives income effects in between those of the models with $\rho=0.85$ and $\rho=0.95$. 
On the other hand, the columns in Table 13 except the last one show that the discount rate hardly affects the estimates of the substitution effects. The effects in the final column of this table, the simulation mimicking the generous early retirement opportunities of the nineties, are a combination of (negative) income and (negative) substitution effects. Accordingly, model M5 with the largest negative income effects also gives the largest negative effect of changing from actuarially fair trade-offs to this system that rewards early retirement. In Model $M 4$ the negative income effect is much smaller, leading to a total effect that is also much smaller than according to the model with estimated discount rate. This leads to the conclusion that fixing the discount rate to the wrong value may bias the estimates of the effects of policy simulations.

\section{Conclusion}

Our paper analyzes retirement preferences using stated preference data. We work with unbalanced panel data on Dutch individuals, collected in 2006, 2007 and 2008. In each year, respondents evaluated four types of hypothetical retirement scenarios - standard retirement (age 65), late full retirement, early full retirement and partial retirement. To study the preferences over different retirement trajectories in detail, we use an intertemporal utility model of labour force participation and income for periods of work and retirement. The model is estimated by simulated maximum likelihood.

One of the main findings is that people prefer gradual retirement trajectories to the benchmark retirement trajectory (retirement age 65, replacement rate $70 \%$ ), although these offer actuarially less income than the benchmark trajectory. Most people do not wish to work full time to high ages even if relatively high income in retirement period is offered. The fraction of people willing to work very long can be increased if we allow for gradual retirement. Gradual retirement seems therefore to be an appropriate tool to keep older people working.

Another key finding concerns the change of preferences over time. Taking into account the results presented in both our study and in Van Soest et al. (2006), which uses data collected by CentER in year 2004, we can observe a decrease in preferences for early retirement and an increase in preferences for late retirement in period 2004-2008. This may reflect changes in social norms.

We study the income effect on preferred retirement age. First, we let people choose between retirement scenarios with full retirement at ages between $60-70$ years which are actuarially equivalent to the benchmark scenario. Then people could 
choose between all actuarially neutral scenarios with higher or lower pension income levels than in the benchmark choice set. We find that the income effect is negative and substantial. The preferred retirement age for the benchmark choice set is 65.1 years. The increase of pension income by $10 \%$ lowers the preferred retirement age by 3 months. A decrease of the income by $10 \%$ increases the preferred retirement age by 3.2 months.

Similarly, we calculate the substitution effect by changing the accruals, keeping the replacement rate when retiring at the normal retirement age of 65 at its benchmark value of $70 \%$. We find substantial substitution effects. For example, reducing the accruals to half their actuarially neutral values would reduce the average retirement age by almost 10 months. The results also explain the popularity of generous early retirement opportunities as they existed in the Netherlands until the nineties - according to our simulations they reduced the average retirement age of those who had access to them by almost 2.5 years.

Our model can be extended in several ways. It would be reasonable to include for example savings or joint decision making of spouses. Changing the formulation of the hypothetical retirement scenarios should be considered, to make the hypothetical retirement options more understandable for the surveyed people.

\section{References}

Barsky R, Juster F, Kimball M, Shapiro M. 1997. Preference parameters and behavioral heterogeneity: An experimental approach in the health and retirement study. Quarterly Journal of Economics : 537-579.

Belloni M, Monticone C, Trucchi S. 2006. Flexibility in retirement. A framework for the analysis and a survey of European countries. Research report commissioned by the European Commission, CeRP, Turin.

Bovenberg A, Gradus R. 2008. Dutch policies towards ageing. European View : $265-275$.

Brown J, Coile C, Weisbenner S. 2006. The effect of inheritance receipt on retirement. NBER working paper 12386, NBER, Cambridge MA.

Bruinshoofd W, Grob S. 2005. Arbeidsparticipatie van ouderen: Microfinanciële motivaties en beleidsaspecten. DNB Occasional Studies, vol. 3, no. 1, De Nederlandsche Bank, Amsterdam. 
Capretta J. 2007. Global aging and the sustainability of public pension systems an assessment of reform efforts in twelve developed countries. Technical report, Center for Strategic \& International Studies, Washington.

Euwals R, van Vuuren D, Wolthoff R. 2007. Early retirement behaviour in the Netherlands. Netpsar Discussion Paper 2007-013.

Fouarge D, Kerkhofs M, Ester P. 2008. The effect of financial incentives on pension age: Results from a stated preferences experiment. Paper presented at the EALE conference.

Gourieroux C, Monfort A. 1991. Simulation based inference in models with heterogeneity. Annales d'Economie et de Statistique 20/21: 69-107.

Gourieroux C, Monfort A. 1996. Simulation-Based Econometric Methods. Oxford: Oxford University Press.

Gruber J, Wise D. 1998. Social security and retirement: An international comparison. American Economic Review : 158-163.

Gruber J, Wise D. 2004. Introduction and summary. In Gruber J, Wise D (eds.) Social Security Programs and Retirement around the World: Micro-Estimation. National Bureau of Economic research, Chicago, 1-40.

Heyma A. 2004. A structural dynamic analysis of retirement behaviour in the Netherlands. Journal of Applied Econometrics : 739-759.

Kakes J, Broeders D. 2006. The sustainability of the Dutch pension system. DNB Occational Studies 06, Nederlands Central Bank.

Kantarci T, Van Soest A. 2008. Gradual retirement: Preferences and limitations. De Economist : 113-144.

Kapteyn A, De Vos K. 1998. Social security and labor force participation in the Netherlands. American Economic Review : 164-167.

Kapteyn A, De Vos K. 2004. Incentives and exit routes to retirement in the Netherlands. In Gruber J, Wise D (eds.) Social Security Programs and Retirement around the World: Micro-Estimation. National Bureau of Economic research, Chicago, 461-498.

Louviere J, Hensher D, Swait J. 2002. Stated Choice Methods. Cambridge: Cambridge University Press. 
Lumsdaine R, Mitchell O. 1999. New developments in the economic analysis of retirement. In Ashenfelter O, Card D (eds.) Handbook of Labor Economics, Vol. 3C. North-Holland, Amsterdam, 3261-3307.

Mastrogiacomo M, Alessie R, Lindeboom M. 2004. Retirement behaviour of Dutch elderly households. Journal of Applied Econometrics 19: 777-793.

Nelissen J. 2001. Het effect van wijzigingen in vervroegde uittredingsregelingen op de arbeidsparticipatie van oudere werknemers. Ministry of Social Affairs and Employment, The Hague.

Queisser M, Whitehouse E. 2006. Neutral or fair? Acturial concepts and pensionsystem design. OECD Social, employment and migration working paper 40, OECD.

Revelt D, Train K. 1998. Mixed logit with repeated choices: Household choices of appliance efficiency level. Review of Economics and Statistics : 647-657.

Train K. 2003. Discrete Choice Methods with Simulation. Cambridge: Cambridge University Press.

Van Dalen H, Henkens K, Hershey D. 2008. Are pension savings sufficient? Perceptions and expectations of American and Dutch workers. CentER discussion paper 2008-58, Tilburg.

Van Soest A, Kapteyn A, Zissimopoulos J. 2006. Using stated preferences data to analyze preferences for full and partial retirement. DNB working paper 081, Netherlands Central Bank, Research Department.

Van Solinge H, Henkens K. 2007. Involuntary retirement: The role of restrictive circumstances, timing, social embeddedness and control. Journal of Gerontology: Social Sciences : S295-S305. 